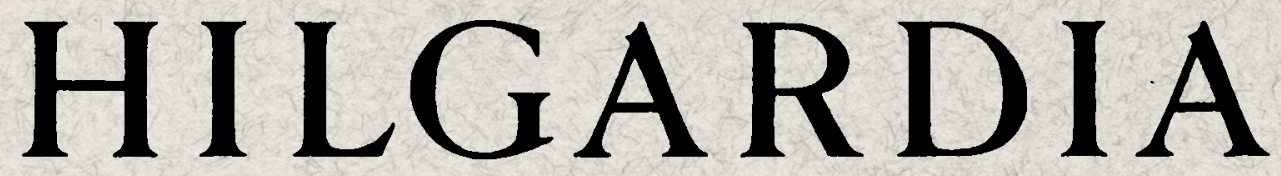

A Journal of Agricultural Science Publisbed by the California Agricultural Experiment Station

\title{
INCOME, PRICE, AND YIELD VARIABILITY FOR PRINCIPAL CALIFORNIA CROPS AND CROPPING SYSTEMS
}

\author{
H. O. CARTER \\ and \\ G. W. DEAN
}




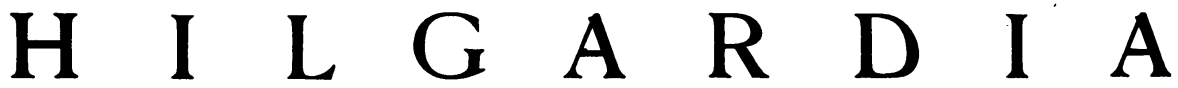

A Journal of Agricultural Science Published by

the California Agricultural Experiment Station

VOL. 30

OCTOBER, 1960

No. 6

\section{INCOME, PRICE, AND YIELD VARIABILITY FOR PRINCIPAL CALIFORNIA CROPS AND CROPPING SYSTEMS ${ }^{1}$}

\author{
H. O. CARTER ${ }^{2}$ and G. W. DEAN ${ }^{3}$
}

\section{INTRODUCTION}

Favorable soil and climatic conditions in California enable the majority of farmers to select from among many different types of crops and cropping systems. Other considerations such as access to markets, specialized abilities and experiences, availability of labor and mechanical equipment, and relative product and resource prices which may give individual managers comparative advantages also influence the farm manager's decisions. Another important factor in selecting cropping systems is the manager's attitude toward the "uncertainty" or "risk" associated with different crops; with respect to price and yield, some crops are "high risk" while others are "low risk." Managers' views concerning the uncertainties of crop production are strongly influenced by past experience. However, experience is often limited (e.g., in the case of new farmers), or based on a "biased" sample of unusual years. Therefore, the purpose of this study is to provide a more objective measurement of the "uncertainty" or variability associated with various crops and cropping systems in California.

\section{Risk and Uncertainty}

Following Knight (1921), ${ }^{4}$ risk and uncertainty are distinguished as two different phenomena. Risk refers to situations where parameters (such as the mean and variance) of the probability distribution of outcomes can be estimated so as to be actuarially insurable ; in other words, the variability of outcomes can be measured empirically or quantitatively. Uncertainty, on the other hand, refers to those situations in which the parameters of the probability distribution of outcomes cannot be empirically or quantitatively determined.

\footnotetext{
${ }^{1}$ Submitted for publication March 27, 1959.

${ }^{2}$ Assistant Professor of Agricultural Economics and Assistant Agricultural Economist in the Experiment Station and on the Giannini Foundation, Davis.

${ }^{3}$ Assistant Professor of Agricultural Economies and Assistant Agricultural Economist in the Experiment Station and on the Giannini Foundation, Davis.

"See "Literature cited" for citations, referred to in the text by author and date.
} 
This study assumes that certain parameters of the distributions of crop prices, yields, and incomes can be established empirically. Measures of the variability of prices, yields, and incomes are computed on the basis of 20 to 40 years of historical data. The parameter used to characterize the variability associated with various crops and cropping systems is the variance of the random portion as defined later of each time series.

While empirical variability estimates are not necessarily identical with the traditional concept of either "risk" or "uncertainty," they are objective measures of past variability in crop production. Assuming that future variability of particular crops is closely related to past variability, empirical variability estimates should provide a more reasonable basis for making both short-run and long-run cropping decisions.

Three types of crop variability are considered in this study:

Price Variability. Product and input prices are subject to variability from a number of sources. In California, certain products, notably those under government programs, have relatively stable prices. However, other products-for example, certain perishable fruits and vegetables-exhibit extreme price variation.

Yield Variability. Yield variability arises from uncertain weather conditions, disease, insect and weed problems, resource availability (e.g., labor) and technological change. Yield variability of irrigated crops in California usually is less than for dryland farmed crops.

Income Variability. Income variability per acre arises from the interaction of product yield per acre and product prices relative to costs. Variability in income is of primary interest to California farmers.

\section{Objectives}

This study estimates the degree of variability in yields, prices and incomes associated with various types of erop production in California and investigates the relationships between stability and level of farm income from particular cropping systems. Knowledge of these relationships is prerequisite to rational choices among crops or combinations of crops to produce. For example, farmers must decide whether to produce: a) high income crops with a correspondingly high risk of large losses and possible bankruptcy, b) lower risk crops with lower average income, c) a combination of high and low risk crops. New farmers, farmers with limited capital or farmers who prefer not to gamble on high-risk crops could choose crop combinations which minimize risk, thus avoiding the short-run possibility of bankruptcy and thereby remain in farming for longer-run gains. Established farmers or those with high risk preferences might concentrate on high-risk crops. Again this choice also may be rational ; in the minds of such farmers, high "possible" incomes offset greater probabilities of large losses.

In line with these general goals, the specific objectives of this study are:

1. To estimate absolute and relative variability of product prices, yields, and gross income of major field crops, vegetables, fruit, and nut crops in California.

2. To compare various crop diversification systems from the standpoint of variability and level of income between and within selected farming areas. 


\section{Measurement of Variability}

Variability in crop production stems from the fact that yields, prices and incomes are influenced by many variables in an unpredictable or "random" manner. From the standpoint of the individual farmer, what portion of the total variation in price, yield and income is unpredictable or "random" and what portion predictable ${ }^{5}$ Some research workers believe that in the eyes of the farmer any deviation from the long-run mean is a random or unpredictable event. Such an approach essentially represents a "no knowledge" situation. It is more realistic to assume that farmers recognize certain longrun physical and economic trends-e.g., technological advances, inflation, and price cycles. Thus, farmers planning crop production for the year ahead are more likely to view the "random" element as a deviation from the "current level" (e.g., of prices or yields over the last five years) rather than as a deviation from the long-run mean.

However, there are several alternative empirical procedures for determining the exact "current level" of the time series (and hence for determining the deviations from this "current level"). A familiar technique is to approximate the "current level" of the time series by a fitted trend line, and then to assume that deviations from the trend represent the "random" component (Heady, 1954). A second method is to assume that the "current level" is identical with the previous year. In this case, the "random" element is identical with first differences of the data (Kling, 1942). A third procedure approximates the "current level" by a moving average, and then assumes that deviations from the moving average are the "random" element. Finally, a series might be deflated by some general index to arrive at "real" values of the series; deviations from the long-run mean of the deflated series represent the "random" element. (This procedure is useful primarily in price series; e.g., deflating prices by some measure of the general price level such as the wholesale price index.)

There are arguments for and against each of the alternative procedures. The authors believe that the most reasonable of these is the trend removal method which is based on the assumption that the systematic component of the time series (i.e., general price level, technological trend, etc.) can be characterized by linear, polynomial or other types of mathematical functions. The authors prefer a statistical method that does not require $a$ priori specification of rigid functions. Because the variate difference method appears to meet this objection, it is the technique employed in this study (Tintner, $1940)$.

The fundamental assumption of the variate difference method is that every time series essentially consists of two additive parts. The first part is the mathematical expectation or systematic component of the time series in which consecutive observations are positively correlated with each other. Although the procedure is not restricted to time series showing a positive trend-a negatively sloped line also produces positively correlated consecutive obser-

\footnotetext{
${ }^{5}$ It is recognized that certain fluctuations which might be classed as unpredictable or "random" to the individual farmer could in fact be "explained" by appropriate aggregate supply and price analysis.
} 
vations-the method is inappropriate for excessively "zigzag" series. The second part is the random or unpredictable component where consecutive items are assumed not to be autocorrelated or correlated with the systematic component (Tintner, 1952). ${ }^{\circ}$ The variate difference method separates the random component from the systematic component of time series. The method avoids unnecessary assumptions about the functional character of the systematic component. We assume that the smooth part of the time series (the systematic component) can be approximated by polynominals of the variable time which otherwise need not be specified. A well known theorem regarding a polynomial of degree $m$ is that its $\mathrm{m}^{\text {th }}$ finite difference is constant and its $m+1, m+2, \ldots$ finite differences vanish. However, this does not hold for the random elements which cannot be reduced by finite differencing since they are not ordered in time (i.e., they cannot be approximated by a smooth function). Accordingly, the method eliminates the systematic component by successive finite differencing, leaving an estimate of the random element.

The procedure consists of calculating the variance of the original series and of each of the series of successive finite differences. Then the difference between variances of two successive series of finite differences is compared with its standard error. Tintner states that if the difference is smaller than three times its standard error, the probability is that the finite differencing has been carried far enough to yield a valid variance estimate of the random component. ${ }^{7}$

\section{Procedure and Sources of Data}

Two facets of variability are considered in this study: (1) a comprehensive comparison of crop variability measures in regard to yield, price and gross income and (2) relative levels and variability of net income associated with selected cropping systems in major agricultural areas of California.

Variability measures of individual crops were derived exclusively from state yield, price and income series. Due to data limitations no other alternative appeared feasible. For certain crops, yield variability may differ because of regional differences in climate, resources, and economic conditions. In these cases, the variability measures derived from state data may not accurately represent regional variability, a serious limitation for certain field crops grown throughout the state. The limitation is less serious for fruit and vegetable crops concentrated in localized areas. An additional problem is that since "random" fluctuations on individual farms may be partially averaged or "evened-out" in compiling the state yield series part of the variability is eliminated. Conversely, variability measures based on historical yields from individual farms may overestimate the "true" variability. That is, the individual farmer's capital position, tenure arrangements, managerial ability

\footnotetext{
${ }^{6}$ It should be emphasized that the variate difference method is only applicable if there is no autocorrelation in the random element.

${ }^{7}$ For a brief mathematical exposition of the variate difference method, see Appendix C. The variate difference method also contains certain problems and limitations which should be recognized. A problem unique to the variate difference method is that in short time series, the selection of the difference providing the estimate of the random variance is not clear-cut on statistical grounds and requires judgment by the investigator. Other problems and limitations are discussed in more detail in Appendix C.
} 
and other influencing factors may be confused with year-to-year "random" yield fluctuations. Although statistical sampling procedures could minimize the latter problems, very few farmers have compiled the necessary historical yield records. ${ }^{8}$

Use of state price series does not significantly misrepresent prices received by individual farmers except in the case of certain fresh fruit and vegetable crops whose prices vary widely during a single shipping season. In this case the seasonal average price may be applicable since many farmers ship perishable crops at regular intervals throughout the harvesting season. Undoubtedly, for many crops the intraseason price variation is an important problem. However, the present study is limited to an examination of yearly price variability.

The second section of this report deals with the relative levels and variability of net income associated with combinations of crops (eropping systems) for several representative cropping systems employed in several agricultural regions of California.

\section{YIELD, PRICE, AND GROSS INCOME VARIABILITY OF SELECTED CALIFORNIA CROPS}

This section contains empirical estimates of the relative yield, price, and gross income variability of selected field crops, vegetables, and fruit and nut crops grown in California. Except for a limited number of crops with shorter recorded histories, basic data consist of annual state averages for the years 1918-1957. As already noted, the variate difference method is employed to obtain estimates of the variance of the random or "unpredictable" portion of total variance in crop yields, prices and gross incomes; that is, "unpredictable" from the standpoint of the individual farmer. Equation (1) defines

$$
\text { (1) Variability coefficient }=\frac{\sqrt{\text { variance }}}{1953-1957 \text { mean }} \times 100
$$

the "variability coefficient" used as a measure of the variability of one crop relative to others. ${ }^{9}$ Thus, the variability coefficient measures the standard deviation as a percentage of recent mean levels for each series; variability relative to recent levels appears most meaningful for future planning and decisionmaking.

The question arises as to whether the computed variance is homogeneous with respect to time or whether, in fact, the variance has increased or de-

${ }^{8} \mathrm{~A}$ further methodological problem is that the variability measures may be influenced to some extent by the number of farm units growing the particular erop. See Appendix C for a detailed treatment of this problem.

"The "variability coefficient" differs from the widely-used "coefficient of variation" only in that the variance and mean are defined somewhat differently. In equation (1), "variance" refers to the variance of the "random" portion of a time series as computed by the variate difference method; the mean is computed as the mean of the last 5 years. In the "coefficient of variation," the variance and mean are computed in the usual manner from the original series. The difference between the variability coefficient (equation 1 ) and a measure Tintner calls the coefficient of random variation is that the latter measure uses an over-all mean rather than $1953-1957$. 
creased over time. Tables in Appendix A set forth the results of a test of homogeneity of variance over time. Bartlett's test (Snedecor, 1946) ${ }^{10}$ is used to indicate whether the variance for 1918-1937 is significantly different from that for 1938-1957. Where no statistically significant difference is detected by the test, the variance based on the 1918-1957 period is used in computing the "variability coefficient." Where a difference in variance is detected, the "variability coefficient" is based on the variance computed only from 19381957 data. Thus, where variance is not homogeneous, the variance based on the most recent period is taken as the best estimate of future variance. The division of the time period into two 20 -year periods, a procedure with obvious limitations, was based primarily on statistical considerations. Suppose, for example, that the variance of a yield series has been declining continuously over time due to advances in technology. Bartlett's test might detect a difference in variance between the two time periods, yet the true variance at the present time would be lower than the estimate even for the most recent 20year period. However, the authors doubt that the estimates derived would have been substantially improved if the total period had been divided into more sub-periods.

\section{Yield Variability of California Crops}

The yields of practically all California crops have been increasing as a result of technological developments (irrigation, improved crop varieties, certified seed, fertilizer, mechanization, etc.) and increased inputs. For certain crops, the upward trend has been linear; for others the trend has assumed various curvilinear forms. In this study, only yield fluctuations not associated with trend are assumed to be random or unpredictable to the farmer.

Do yield variability measures computed from state data accurately reflect the yield variabilities faced by individual farmers? Ideally, yield variances would be based on a large sample of individual farm yields occurring under the present general level of technology, prices and costs, but subject to the impacts of random variables. Such a procedure would employ a combination of cross section and time series data over a limited period of years. In practice, the time and cost required to collect such data is prohibitive. However, even with such individual farm data, year-to-year changes in practices and input levels would affect yields in a nonrandom manner. Thus, despite certain limitations such as the possibility of "averaging out" individual farm yield variations, state data used in this study are expected to provide reasonable estimates of relative yield variabilities. No attempt is made to explain smali differences in relative variability between crops; only major and apparently significant differences between crops are discussed.

Field crops. Table 1 presents variability coefficients for nine major field crops grown in California, ranging from least variable (alfalfa) to most variable (rice). In general, the yield variability of field crops appears quite low. The ranking corresponds closely with common knowledge concerning relative yield variability of field crops. For example, alfalfa ordinarily is considered a very stable irrigated crop. At the other extreme, rice yield variability is affected by seasonal weather conditions, particularly tempera-

\footnotetext{
${ }^{10}$ Details of Bartlett's test are set forth in most books on statistical methods.
} 
tures during pollinization. Also, insects such as leaf miner, and parasites such as fresh water shrimp can influence yields markedly in particular years.

Vegetables. Yield variabilities for 30 California vegetables are summarized in Table 2. As with field crops, the ranking of the vegetable crops in order of yield variability is as expected. "Most variable" are a number of spring vegetables, most of which are planted from November to February and harvested in the spring. Variable winter weather conditions undoubtedly contribute to the high relative yield uncertainty of these crops. In general, vegetable crops show somewhat greater yield variability than field crops. This difference is probably due to the rather specialized skills, soils, and climate conditions required for successful vegetable production.

TABLE 1

SELECTED FIELD CROPS: RANKING BY YIELD VARIABILITY COEFFICIENTS

\begin{tabular}{|c|c|c|c|c|}
\hline Product & $\begin{array}{l}\text { Variability } \\
\text { coefficient* }\end{array}$ & $\begin{array}{c}\text { Standard } \\
\text { deviation } \dagger\end{array}$ & $\begin{array}{c}1953-57 \\
\text { mean }\end{array}$ & Unit \\
\hline & per cent & & & \\
\hline Alfalfa. . & 3 & 0.13 & 4.62 & tons \\
\hline Barley.......... & 5 & 1.91 & 37.70 & 48-tb bushels \\
\hline Potatoes (late)......... & 6 & 22.01 & 376.00 & 60 -lb bushels \\
\hline Sugar beets.... & 6 & 1.19 & 20.74 & tons \\
\hline 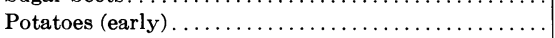 & 6 & 27.86 & 450.00 & 60 -tb bushels \\
\hline Cottonseed $\ldots \ldots \ldots \ldots \ldots \ldots \ldots \ldots \ldots \ldots \ldots \ldots$ & 7 & 0.05 & 0.70 & tons \\
\hline 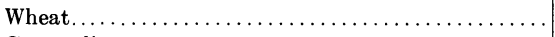 & 7 & 1.40 & 20.50 & 60 -lb bushels \\
\hline Cotton lint $\ldots \ldots \ldots \ldots \ldots \ldots \ldots \ldots \ldots \ldots \ldots \ldots \ldots \ldots \ldots \ldots$ & 9 & 0.72 & 8.28 & cwt. \\
\hline 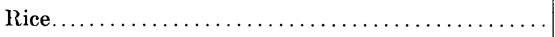 & 10 & 3.38 & 34.40 & cwt. \\
\hline
\end{tabular}

* Variability coefficient $=$ standard deviation (computed from variate difference method) divided by the 1953-57 mean. Computations may not check exactly because data are rounded off for ease in presentation.

+ Standard deviation (computed from variate difference method) computed from 1918-57 annual data where variance is homogeneous over time and from 1938-57 data where variance changes significantly over time. See Appendix A for homogeneity of variance test results.

The above variability estimates are based on yields per harvested acre. However, for certain vegetables, some planted acreage may not be harvested due to economic conditions. Or, if prices are unfavorable, a smaller proportion of the total yield per acre may be harvested. Thus, prices at harvest time and harvested yields per acre tend to be positively correlated. The correlation between price and yield is important in determining gross income variability.

Fruits and nuts. Relative yield variabilities for 19 major California fruit and nut crops are presented in Table 3. The range in yield variability for fruits and nuts is relatively wide-from 5 per cent for grapefruit to 31 per cent for olives. Also, yield variability coefficients average considerably higher for fruits and nuts than for vegetables and field crops. Olives, avocados and apricots rank highest in yield variability as shown in Table 3 . While most fruit and nut crops display an alternate bearing tendency (i.e., large crops followed by small crops and vice versa), the tendency is particularly strong for olive, avocado and apricot crops. On the other hand, grapefruit (the least variable crop) shows very little alternate bearing tendency. Moreover, most California grapefruit is grown in the desert area where environmental factors are quite uniform and predictable. Although freestone peaches (second lowest in yield variability) exhibit an alternate bearing tendency, the magnitude of year-to-year changes are small relative to recent yield levels. In 
general, the ranking of the fruit and nut crops in Table 3 appears to be reasonable.

\section{Price Variability of California Crops}

Price variability undoubtedly exerts an important influence on farmers' planting decisions ("variability" being random or unpredictable fluctua-

TABLE 2

SELECTED VEGETABLES: RANKING BY YIELD VARIABILITY COEFFICIENTS

\begin{tabular}{|c|c|c|c|c|}
\hline Product & $\begin{array}{l}\text { Variability } \\
\text { coefficient* }\end{array}$ & $\begin{array}{c}\text { Standard } \\
\text { deviation } \dagger\end{array}$ & $\begin{array}{c}1953-57 \\
\text { mean }\end{array}$ & Unit \\
\hline & per cent & & & \\
\hline Tomatoes, early fall. & 2 & 10.06 & 526.00 & 32-lb lug \\
\hline Beans, green lima... & 4 & 1.07 & 29.80 & cwt. \\
\hline 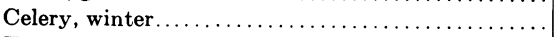 & 5 & 42.80 & 880.00 & 60 - $\mathrm{tb}$ crate \\
\hline 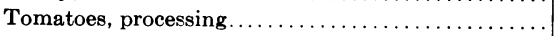 & 5 & 0.87 & 17.10 & tons \\
\hline Onions, late summer $\ldots \ldots \ldots \ldots \ldots \ldots \ldots \ldots$ & 6 & 36.95 & 653.40 & 50-lb sack \\
\hline 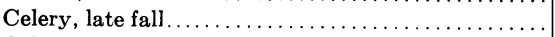 & 6 & 39.46 & 685.00 & $60-\mathrm{tb}$ crate \\
\hline 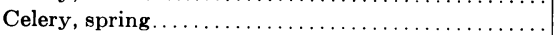 & 6 & 79.25 & $1,300.00$ & 60 - $\mathrm{tb}$ crate \\
\hline 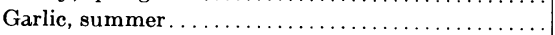 & 6 & 4.73 & 82.00 & $100-\mathrm{tb}$ sack \\
\hline Cauliflower, early spring $\ldots \ldots \ldots \ldots \ldots \ldots \ldots \ldots$ & 7 & 28.13 & 424.20 & $37-\mathrm{tb}$ crate \\
\hline Peppers-Bell, late summer $\ldots \ldots \ldots \ldots \ldots \ldots \ldots \ldots$ & 7 & 31.88 & 470.00 & $25-1 \mathrm{~b} \mathrm{bu}$. \\
\hline Onions, late spring $\ldots \ldots \ldots \ldots \ldots \ldots \ldots \ldots$ & 7 & 46.47 & 624.20 & $50-\mathrm{tb}$ sack \\
\hline Lettuce, early fall ........................ & 8 & 14.99 & 191.00 & $70-\mathrm{lb}$ crate \\
\hline Strawberries, mid spring . . . . . $\ldots \ldots \ldots \ldots \ldots$ & 9 & 121.72 & $1,334.20$ & 12-pt. tray \\
\hline Honeydews, late summer................... & 9 & 29.37 & 321.00 & 40 -tb crate \\
\hline Carrots, early summer.................. & 9 & 30.40 & 352.00 & 75-lb crate \\
\hline 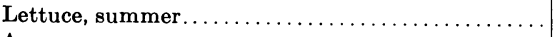 & 9 & 26.27 & 294.00 & 70 -tb crate \\
\hline 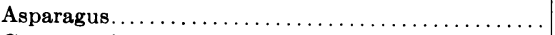 & 9 & 0.10 & 1.17 & tons \\
\hline Carrots, winter..................... & 9 & 29.19 & 312.00 & 75-lb crate \\
\hline Cauliflower, late fall.. & 10 & 42.78 & 412.00 & $37-\mathrm{tb}$ crate \\
\hline Snap beans, early fall. ..... & 10 & 38.49 & 379.00 & $30-\mathrm{lb}$ bu. \\
\hline Tomatoes, early summer ..................... & 11 & 48.06 & 432.00 & 32 -lb lug \\
\hline Tomatoes, early spring $\ldots \ldots \ldots \ldots \ldots \ldots \ldots \ldots \ldots$ & 11 & 55.93 & 502.40 & 32 -lb lug \\
\hline Cabbage, early spring $\ldots \ldots \ldots \ldots \ldots \ldots \ldots \ldots \ldots$ & 11 & 1.16 & 10.09 & tons \\
\hline Cantaloupes, mid summer. $\ldots \ldots \ldots \ldots \ldots \ldots \ldots \ldots$ & 12 & 21.84 & 180.00 & 80 -lb crate \\
\hline 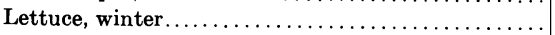 & 12 & 22.40 & 193.00 & 70 -lb crate \\
\hline Broccoli, early spring $\ldots \ldots \ldots \ldots \ldots \ldots \ldots \ldots \ldots$ & 12 & 17.20 & 146.00 & $42-1 \mathrm{~b}$ crate \\
\hline Carrots, late fall $\ldots \ldots \ldots \ldots \ldots \ldots \ldots \ldots \ldots \ldots \ldots$ & 13 & 45.55 & 343.00 & 75-lb crate \\
\hline Lettuce, early spring . . . . . . . $\ldots \ldots \ldots \ldots \ldots \ldots$ & 15 & 23.90 & 155.00 & 70-lb crate \\
\hline Cantaloupes, spring $\ldots \ldots \ldots \ldots \ldots \ldots \ldots \ldots \ldots \ldots$ & 16 & 18.00 & 116.00 & 80 -lb crate \\
\hline Watermelons, late spring. $\ldots \ldots \ldots \ldots \ldots \ldots \ldots \ldots$ & 16 & 1.03 & 6.46 & tons \\
\hline
\end{tabular}

* Variability coefficient $=$ standard deviation (computed from variate difference method) divided by the 1953-57 mean. Computations may not check exactly because data are rounded off for ease in presentation.

$\dagger$ Standard deviation (computed from variate difference method) computed from 1918-57 annual data where variance is homogeneous over time and from 1938-57 data where variance changes significantly over time. See Appendix A for homogeneity of variance test results.

tion). In this study, year-to-year fluctuation in prices (with trend removed through the variate difference method) is treated as the variability relevant for planting decisions by individual farmers. ${ }^{11}$ The argument for trend removal appears strong because otherwise all price fluctuations away from the long-run average would be considered unpredictable. ${ }^{12}$ Farmers probably

${ }^{11}$ Of course, appropriate aggregate analysis could probably isolate economic determinants of a major portion of the total year-to-year price fluctuation. Yet the standard errors attached to price forecasts from econometric demand functions (even those with a high degree of "fit" to past data) are extremely large. It seems doubtful that the individual farmer could predict prices within narrower limits.

12 "Long-run average price" refers to the average price for the period 1918-1957. 
expect prices to fluctuate about the recent level and not about the long-run average price. For example, the prices of many California products have trended upward so sharply for a long period that a price as low as the longrun mean is not expected in the near future.

Field crops. Table 4 presents the price variability coefficients for nine major California field crops. Crops with the lowest price variability coefficients (wheat, sugar beets, rice and barley) are those which have been sub-

TABLE 3

SELECTED FRUITS AND NUTS: RANKING BY YIELD VARIABILITY COEFFICIENTS

\begin{tabular}{|c|c|c|c|c|}
\hline Product & $\begin{array}{l}\text { Variability } \\
\text { coefficient* }\end{array}$ & $\begin{array}{c}\text { Standard } \\
\text { deviation } \dagger\end{array}$ & $\begin{array}{r}1953-57 \\
\text { mean } \ddagger\end{array}$ & Unit \\
\hline & per cent & & & \\
\hline Grapefruit. & 5 & 15.39 & 296.80 & boxes \\
\hline Peaches, freestone $\ldots \ldots \ldots \ldots \ldots \ldots \ldots \ldots \ldots \ldots \ldots \ldots \ldots \ldots \ldots \ldots$ & 7 & 0.64 & 8.90 & tons \\
\hline Figs................. & 9 & 0.32 & 3.50 & tons \\
\hline Grapes............. & 10 & 0.60 & 6.04 & tons \\
\hline Peaches, clingstone.... & 10 & 1.22 & 11.90 & tons \\
\hline 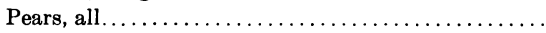 & 11 & 1.07 & 9.70 & tons \\
\hline Lemons............... & 11 & 30.89 & 273.80 & boxes \\
\hline Oranges, navel....... & 13 & 29.65 & 222.80 & boxes \\
\hline Plums............. & 13 & 0.52 & 3.86 & tons \\
\hline Prunes.............. & 14 & 0.26 & 1.82 & tons \\
\hline Oranges, valencia $\ldots \ldots \ldots \ldots \ldots \ldots \ldots \ldots \ldots \ldots$ & 17 & 36.49 & 210.00 & boxes \\
\hline Almonds & 19 & 0.09 & 0.48 & tons \\
\hline 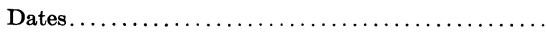 & 19 & 0.81 & 4.20 & tons \\
\hline Apples $\ldots \ldots \ldots \ldots \ldots \ldots \ldots \ldots \ldots \ldots \ldots \ldots \ldots$ & 21 & 82.87 & 390.60 & bushels \\
\hline 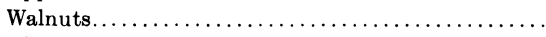 & 21 & 0.12 & 0.57 & tons \\
\hline 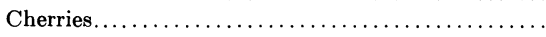 & 24 & 0.76 & 3.20 & tons \\
\hline Apricots $\ldots \ldots \ldots \ldots \ldots \ldots \ldots \ldots \ldots$ & 27 & 1.36 & 5.00 & tons \\
\hline Avocados........... & 29 & 0.46 & 1.56 & tons \\
\hline Olives............... & 31 & 0.49 & 1.58 & tons \\
\hline
\end{tabular}

* Variabiilty coefficient $=$ standard deviation (computed from variate difference method) divided by the 1953-57 mean. Computations may not check exactly because data are rounded off for ease in presentation.

$\dagger$ Standard deviation (computed from variate difference method computed from 1918-57 annual data where variance is homogeneous over time and from 1938-57 data where variance changes significantly over time. See Appendix $\mathrm{A}$ for homogeneity of variance test results.

$\ddagger$ Grapef ruit, lemons, navel and valencia oranges, 1952-56 mean. 1957 data not available.

jected to a considerable degree of direct governmental control over a long period. Government price controls for cotton which have been of relatively short duration (1950 and 1954-1958) will, if continued, determine future price variability. At the other extreme, the price of early potatoes is commonly considered to be very "risky." California is the major supplier of potatoes in the United States for a six-week period (from about May 15 to June 30). Because of the tendency of California producers to "over-respond" to the previous year's potato prices, leading to a cobweb acreage and price pattern over time, there has been great price variability for the crop (McCorkle, 1956). Thus, the relative variability of the various field crops appears quite reasonable.

Vegetables. Relative price variabilities for 30 selected California vegetable crops are presented in Table 5. Many California vegetables fall in the category of specialty crops produced for specific and often limited markets. Cali- 
fornia producers take advantage of virtually year-around growing conditions to supply certain vegetables when the supply from competing areas is limited. Hence, although California is the major vegetable producing state, California vegetable prices to an important extent depend on supply conditions elsewhere. A number of the vegetables in the upper range of price variability (Table 5) fall in this specialized category. On the other hand, the two major processing vegetables (tomatoes and asparagus) rank extremely low in price

TABLE 4

SELECTED FIELD CROPS: RANKING BY PRICE VARIABILITY COEFFICIENTS

\begin{tabular}{|c|c|c|c|c|}
\hline Product & $\begin{array}{l}\text { Variability } \\
\text { coefficient* }\end{array}$ & $\begin{array}{c}\text { Standard } \\
\text { deviation } \dagger\end{array}$ & $\begin{array}{r}1953-57 \\
\text { mean } \ddagger\end{array}$ & Unit \\
\hline & per cent & & & \\
\hline Wheat.. & 4 & 0.09 & 2.08 & $\$ / 60-\mathrm{tb}$ bu. \\
\hline Sugar beets.......... & 6 & 0.64 & 11.42 & $\$ /$ ton \\
\hline 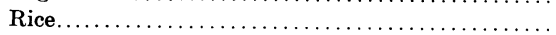 & 10 & 0.49 & 4.65 & $\$ /$ cwt. \\
\hline Barley $\ldots \ldots \ldots \ldots \ldots \ldots \ldots \ldots \ldots \ldots \ldots \ldots$ & 10 & 0.11 & 1.12 & $\$ / 48-\mathrm{tb}$ bu. \\
\hline Alfalfa $\ldots \ldots \ldots \ldots \ldots \ldots \ldots \ldots \ldots \ldots \ldots \ldots \ldots$ & 11 & 2.56 & 23.20 & $\$ /$ ton \\
\hline 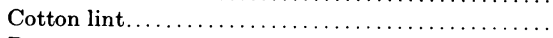 & 11 & 3.57 & 33.28 & $\$ /$ cwt. \\
\hline Potatoes (late)....... & 19 & 0.28 & 1.44 & $\$ 60-\mathrm{tb}$ bu. \\
\hline Cottonseed.......... & 27 & 14.79 & 54.64 & $\$ /$ ton \\
\hline Potatoes (early)...... & 43 & 0.62 & 1.42 & $\$ / 60-\mathrm{lb}$ bu. \\
\hline
\end{tabular}

* Variability coefficient $=$ standard deviation (computed from variate difference method) divided by the 1953-57 mean. Computations may not check exactly because data are rounded off for ease in presentation.

$\dagger$ Standard deviation (computed from variate difference method) computed from 1918-57 annual data where variance is homogeneous over time and from 1938-57 data where variance changes significantly over time. See Appendix A for homogeneity of variance test results.

$\ddagger$ Sugar beets mean based on $1952-56$ prices. 1957 data not available.

variability. Canneries and freezers which are located near growing districts, provide a stable outlet for processed vegetables. In fact, the prices of many processed vegetables (e.g., tomatoes) are determined before the growing season through contracts between producers and processors.

Fruits and nuts. Table 6 ranks 19 California fruit and nut crops according to relative price variability. Grapes, lemons, and olives rank highest in relative variability while a large number of fruits and nuts are grouped at the lower end of the variability scale. Since grape prices have fluctuated violently in the past 20 years, it is not surprising that grapes are the fruit crop with highest price variability. Raisin and wine outlets for grapes are highly interrelated; an oversupply or decline in demand for either affects prices for all grapes. Lemons, the second most "price-variable" fruit, also has shown wide price fluctuations in the past. A California state marketing order for lemon products, initiated in 1950 and since eliminated, did not significantly lessen price variability. However, the possibility that price-stabilizing marketing orders and agreements might be initiated for particular crops should be considered in estimating future price variabilities. The high price variability of olives can be traced largely to wide fluctuations in yields. (olives ranked highest in yield variability among the fruits, Table 3 ).

Fruit and nut crops in the low price-variability range have one or more stabilizing influences. Two examples might be cited: Grapefruit prices are stabilized because grapefruit production changes little from year-to-year (grapefruit ranked lowest in both yield and price variability); walnuts, 
although high in yield variability (Table 3 ), tend to be stabilized in price by a Federal Marketing Order and by a strong grower-owned cooperative which handles a sizable proportion of the total crop.

\section{Gross Income Variability of California Crops}

Ultimately, the farmer is interested in the net income variability of alternative crops and cropping systems. Net income variability, in turn, results

TABLE 5

SELECTED VEGETABLES: RANKING OF PRICE VARIABILITY COEFFICIENTS

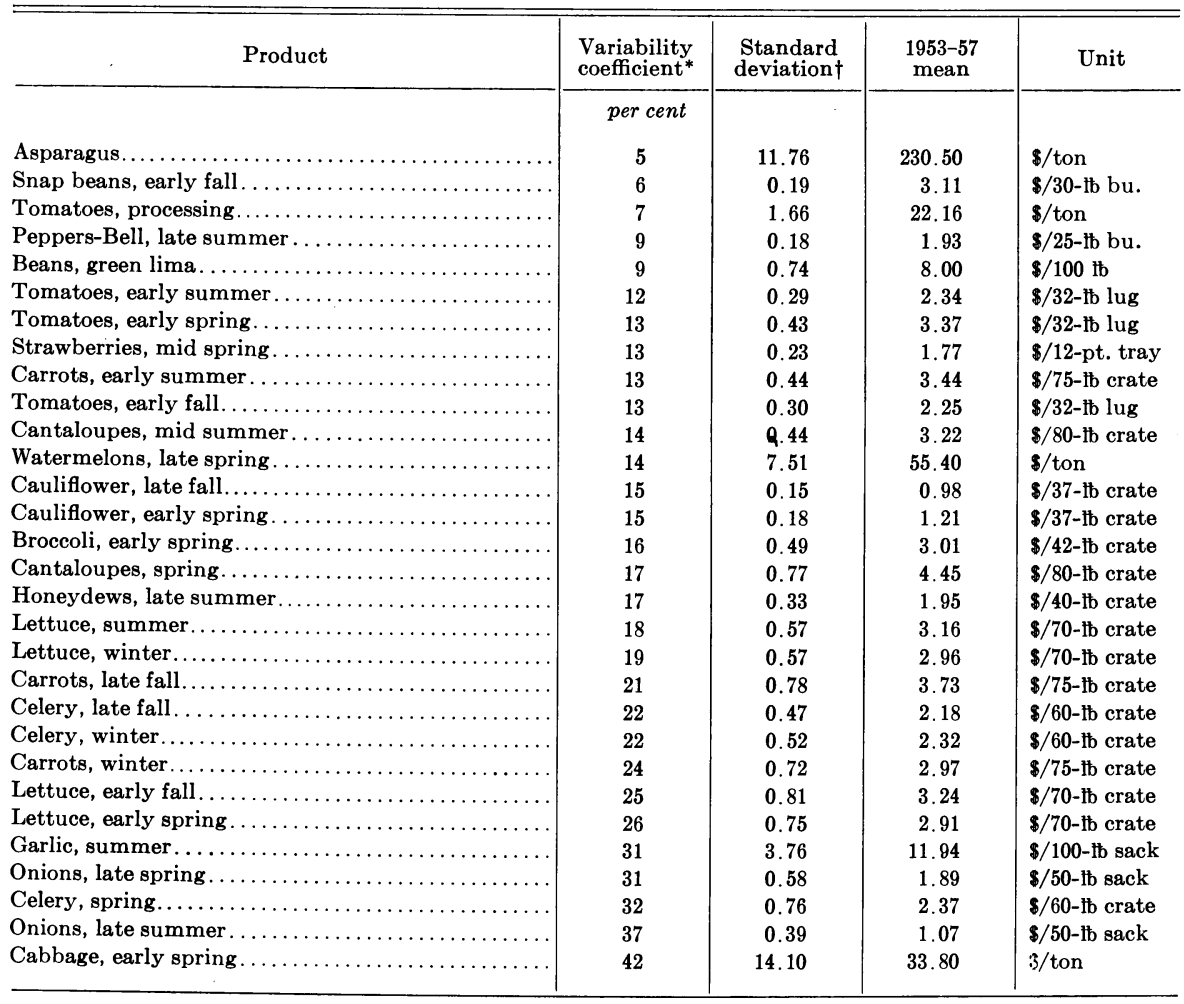

* Variability coefficient $=$ standard deviation (computed from variate difference method) divided by the 1953-57 mean. Computations may not check exactly because data are rounded off for ease in presentation.

$\dagger$ Standard deviation (computed from variate difference method) computed from 1918-57 annual data where variance is homogeneous over time and from 1938-57 data where variance changes significantly over time. See Appendix A for homogeneity of variance test results.

from the interaction of yield, price and cost. The impossibility of obtaining accurate cost data for all individual crops in California over a 40-year period necessitates the use of gross income data in computing crop income variabilities. Where year-to-year costs are relatively stable, crops should have approximately the same relative net income variance as gross income variance. For example, year-to-year costs for field crops are probably relatively constant. However, where harvesting costs are a significant component of total costs and vary with yields per acre, gross income variance may not accurately estimate net income variance for certain vegetable, fruit and nut crops. 
Gross income per acre is computed simply as the product of yield per acre and price. Hence, gross income variability is a function of both price and yield variability. ${ }^{13}$ However, the year-to-year relationship between price and yields also is important. If changes in prices and yields are negatively correlated, high prices tend to be associated with low yields and vice versa, therefore reducing gross income variability. This relationship is observed for many fruits where, with acreage relatively constant from year-to-year, changes in total production (and hence in prices) depend primarily on changes in yields per acre. However, if prices and yields are positively correlated, gross income variability tends to be larger. With positive correlation, high prices accompany large yields and vice versa, adding to the "width of swings" in gross income per acre.

TABLE 6

SELECTED FRUITS AND NUTS: RANKING OF PRICE VARIABILITY COEFFICIENTS

\begin{tabular}{|c|c|c|c|c|}
\hline Product & $\begin{array}{l}\text { Variability } \\
\text { coefficient }\end{array}$ & $\begin{array}{c}\text { Standard } \\
\text { deviation } \dagger\end{array}$ & $\begin{array}{c}1953-57 \\
\text { mean } \ddagger\end{array}$ & Unit \\
\hline & per cent & & & \\
\hline Grapefruit. & 11 & 0.20 & 1.89 & $\$ /$ box \\
\hline Apricots............... & 12 & 13.05 & 112.62 & $\$ /$ ton \\
\hline Walnuts......... & 13 & 59.67 & 449.20 & $\$ /$ ton \\
\hline Peaches, freestone..... & 14 & 9.01 & 65.06 & $\$ /$ ton \\
\hline Prunes.............. & 14 & 30.86 & 218.80 & $\$ /$ ton \\
\hline Oranges, navel $\ldots \ldots \ldots \ldots \ldots \ldots \ldots \ldots \ldots$ & 14 & 0.37 & 2.60 & $\$ /$ box \\
\hline Peaches, clingstone $\ldots \ldots \ldots \ldots \ldots \ldots \ldots \ldots \ldots$ & 15 & 9.88 & 65.00 & $\$ /$ ton \\
\hline 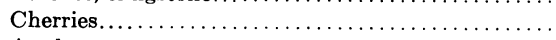 & 17 & 50.71 & 294.80 & $\$ /$ ton \\
\hline 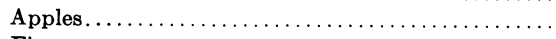 & 17 & 0.25 & 1.49 & $\$ / \mathrm{bu}$. \\
\hline 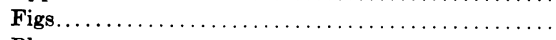 & 20 & 12.33 & 63.06 & $\$ /$ ton \\
\hline Plums........................ & 20 & 27.35 & 134.00 & $\$ /$ ton \\
\hline Oranges, valencia.......... & 20 & 0.50 & 2.46 & $\$ /$ box \\
\hline Almonds.......... & 21 & 134.32 & 626.00 & $\$ /$ ton \\
\hline Dates........... & 21 & 23.64 & 110.00 & $\$ /$ ton \\
\hline Avocados...... & 21 & 73.85 & 356.20 & $\$ /$ ton \\
\hline Pears, all........ & 24 & 17.04 & 71.08 & $\$ /$ ton \\
\hline Olives.............. & 27 & 54.39 & 203.80 & $\$ /$ ton \\
\hline Lemons.............. & 27 & 0.79 & 2.96 & $\$ / \mathrm{box}$ \\
\hline 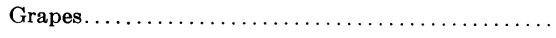 & 31 & 14.40 & 47.02 & $\$ /$ ton \\
\hline
\end{tabular}

* Variability coefficient $=$ standard deviation (computed from variate difference method) divided by the 1953-57 mean. Computations may not check exactly because data are rounded off for ease in presentation.

$\dagger$ Standard deviation (computed from variate difference method) computed from 1918-57 annual data where variance is homogeneous over time and from 1938-57 data where variance changes significantly over time. See Appendix A for homogeneity of variance test results.

‡ Grapefruit, lemons, navel and valencia oranges, 1952-56 mean. 1957 data not available.

Field crops. Table 7 presents gross income variability coefficients for eight California field crops. Gross income is influenced by price and yield variability and by the year-to-year price-yield relationship. Little year-to-year correlation between price and yield is evident for. California field crops. Yield variability for field crops also is relatively low (Table 1). Therefore, the most important factor contributing to gross income variability of field crops is the variability of prices. The rankings of field crops by price and gross income variability are very similar (compare Tables 4 and 7 ): Early and late pota-

${ }^{13}$ Since the variate difference method is used to estimate both yield and price variability, the same method is not strictly applicable for estimating gross income variability. See Appendix $\mathrm{C}$ for a more detailed discussion of this point. 
toes are by far the most variable field crops with respect to both price and gross income; field crops influenced by price stabilizing government programs (sugar beets, barley, wheat and rice) tend to be lowest in gross income variability.

Vegetables. The relative gross income variabilities of 30 major California vegetable crops are presented in Table 8. The ranking of the crops is quite consistent with the yield and price variability results derived earlier (Tables 2 and 5 ). Vegetables low in both price and yield variability are concentrated at the lower end of the gross income variability scale. The most important of these erops in terms of total value are processing tomatoes and asparagus.

TABLE 7

SELECTED FIELD CROPS: RANKING OF GROSS INCOME VARIABILITY COEFFICIENTS

\begin{tabular}{|c|c|c|c|c|}
\hline Product & $\begin{array}{l}\text { Variability } \\
\text { coefficient* }\end{array}$ & $\begin{array}{c}\text { Standard } \\
\text { deviation } \dagger\end{array}$ & $\begin{array}{c}1953-57 \\
\text { mean } \ddagger\end{array}$ & Unit \\
\hline & per cent & & & \\
\hline Sugar beets. & 7 & 14.97 & 227.37 & $\$ /$ acre \\
\hline Barley ........ & 8 & 3.21 & 41.96 & $\$ /$ acre \\
\hline Wheat...... & 8 & $3.57^{\prime}$ & 42.58 & $\$ /$ acre \\
\hline Rice...... & 10 & 16.00 & 158.65 & $\$ /$ acre \\
\hline Alfalfa... & 15 & 15.58 & 107.09 & $\$ /$ acre \\
\hline Cotton.... & 15 & 47.45 & 315.98 & $\$ /$ acre \\
\hline Potatoes (late)....... & 20 & 106.94 & 538.07 & $\$ /$ acre \\
\hline Potatoes (early)....... & 35 & 219.50 & 628.95 & $\$ /$ acre \\
\hline
\end{tabular}

* Variability coefficient $=$ standard deviation (computed from variate difference method) divided by the 1953-57 mean. Computations may not check exactly because data are rounded off for ease in presentation.

$t$ Standard deviation (computed from variate difference method) computed from 1918-57 annual data where variance is homogeneous over time and from 1938-57 data where variance changes significantly over time. See Appendix A for homogeneity of variance test results.

$\ddagger$ Sugar beets mean based on 1952-56 gross income. 1957 data not available.

Crops high in price variability tend to fall in the upper gross income variability range. As with field crops, price variability apparently outweighs yield variability as the major determinant of gross income variability.

Fruits and Nuts. Table 9 ranks 19 major California fruit and nut crops in order of relative gross income variability. The correlation between price and yield for fruits and nut crops is important in determining gross income variability. The argument is as follows: California is by far the major producer of most types of fruits and nuts consumed in the United States. The bearing acreages of these crops change only gradually from year-to-year. Therefore, major year-to-year changes in total production result primarily from changes in California yields. Since the aggregate production-price correlation is ordinarily negative, the yield-price correlation also tends to be negative. Thus, crops which have high individual price and yield variabilities may be relatively stable in gross income because of the offsetting price and yield effect. Cherries, valencia oranges, and avocados provide excellent examples of negative price-yield relationships. These crops display relatively high yield and price variabilities (Tables 3 and 6 ) yet are relatively stable in terms of gross income (Table 9).

On the other hand, dates are the most variable fruit crop in terms of gross income (Table 9), yet the individual yield and price variabilities for dates 
(Tables 3 and 6 ) are only moderately high. The reason lies in a positive yearto-year yield-price relationship since 1940. Date imports were cut off during World War II, and California producers increased yields in response to record prices. Perhaps inclusion of these "abnormal" years in the sample of annual observations tends to provide an over-estimate of gross income vari-

TABLE 8

SELECTED VEGETABLES: RANKING OF GROSS INCOME VARIABILITY COEFFICIENTS

\begin{tabular}{|c|c|c|c|c|}
\hline Product & $\begin{array}{l}\text { Variability } \\
\text { coefficient* }\end{array}$ & $\begin{array}{l}\text { Standard } \\
\text { deviation }\end{array}$ & $\begin{array}{c}1953-57 \\
\text { mean }\end{array}$ & Unit \\
\hline & per cent & & & \\
\hline Snap beans, early fall....... & 7 & 87.01 & $1,175.04$ & \$/acre \\
\hline Tomatoes, processing...... & 8 & 31.05 & 379.59 & $\$ /$ acre \\
\hline Asparagus.................. & 9 & 23.50 & 269.88 & $\$ /$ acre \\
\hline Peppers-Bell, late summer .. & 9 & 82.88 & 908.32 & $\$ /$ acre \\
\hline Tomatoes, early fall.............. & 10 & 118.35 & $1,174.70$ & $\$ /$ acre \\
\hline Beans, green lima $\ldots \ldots \ldots \ldots \ldots \ldots \ldots$ & 10 & 22.49 & 225.34 & $\$ /$ acre \\
\hline Celery, late fall $\ldots \ldots \ldots \ldots \ldots \ldots \ldots \ldots \ldots \ldots$ & 12 & 184.87 & $1,496.73$ & $\$ /$ acre \\
\hline Strawberries, mid spring $\ldots \ldots \ldots \ldots \ldots \ldots \ldots \ldots$ & 13 & 310.62 & $2,370.08$ & $\$ /$ acre \\
\hline 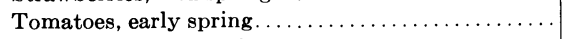 & 13 & 227.43 & $1,689.19$ & $\$ /$ acre \\
\hline Cauliflower, early spring $\ldots \ldots \ldots \ldots \ldots \ldots \ldots \ldots$ & 13 & 66.99 & 514.85 & $\$ /$ acre \\
\hline 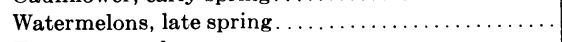 & 15 & 52.57 & 354.60 & $\$ /$ acre \\
\hline 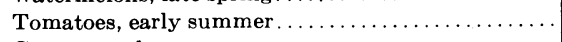 & 15 & 153.60 & $1,018.90$ & $\$ /$ acre \\
\hline 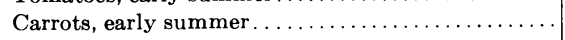 & 16 & 196.33 & $1,218.89$ & $\$ /$ acre \\
\hline 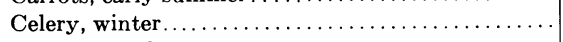 & 17 & 344.01 & $2,044.65$ & $\$ /$ acre \\
\hline 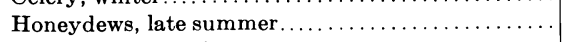 & 17 & 104.66 & 626.62 & $\$ /$ acre \\
\hline Broccoli, early spring $\ldots \ldots \ldots \ldots \ldots \ldots \ldots \ldots$ & 18 & 79.81 & 442.37 & $\$ /$ acre \\
\hline 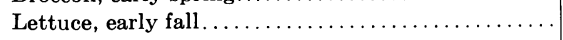 & 19 & 115.39 & 620.77 & $\$ /$ acre \\
\hline Cantaloupes, mid summer. . & 20 & 115.59 & 589.49 & $\$ /$ acre \\
\hline Carrots, late fall................. & 20 & 250.41 & $1,280.58$ & $\$ /$ acre \\
\hline Cauliflower, late fall. & 20 & 82.65 & 406.37 & $\$ /$ acre \\
\hline Onions, late summer. . & 20 & 137.16 & 698.58 & $\$ /$ acre \\
\hline Lettuce, winter........ & 24 & 137.60 & 572.87 & $\$ /$ acre \\
\hline Cantaloupes, spring.... & 26 & 135.36 & 514.89 & $\$ /$ acre \\
\hline Carrots, winter........ & 26 & 245.75 & 934.25 & \$/acre \\
\hline Garlic, summer..... & 27 & 264.72 & 967.03 & $\$ /$ acre \\
\hline Celery, spring......... & 30 & 934.21 & $3,064.74$ & $\$ /$ acre \\
\hline Lettuce, summer..... & 31 & 289.66 & 935.29 & $\$ /$ acre \\
\hline Onions, late spring... & 35 & 419.73 & $1,188.26$ & $\$ /$ acre \\
\hline 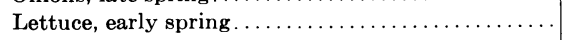 & 41 & 183.95 & 448.31 & $\$ /$ acre \\
\hline Cabbage, early spring $\ldots \ldots \ldots \ldots \ldots \ldots \ldots \ldots$ & 44 & 166.34 & 374.28 & $\$ /$ acre \\
\hline
\end{tabular}

* Variability coefficient $=$ standard deviation (computed from variate difference method) divided by the 1953-57 mean. Computations may not check exactly because data are rounded off for ease in presentation.

ability. However, the same positive year-to-year yield-price correlation has continued in general since World War II. In most instances, the individual yield and price variabilities of California fruit and nut crops are rather poor indicators of gross income variabilities since they ignore significant yieldprice correlations.

\section{CROP DIVERSIFICATION AS A MEANS OF LESSENING INCOME VARIABILITY Principles of Diversification}

Although diversification principles as a means for lessening income variaability have been discussed in the literature, some fundamentals of diversifi- 
cation are given here for purposes of continuity (Heady, 1952, 1954). Diversification can be accomplished in two ways: (1) by adding sufficient resources to include the new enterprise or enterprises without reducing the size of present enterprises (e.g., a farmer in Kern County with 80 acres of potatoes could diversify by planting 80 additional acres of cotton), or (2) by redistributing fixed resources among more enterprises (e.g., 40 acres each of potatoes and cotton instead of 80 acres of potatoes).

TABLE 9

\section{SELECTED FRUITS AND NUTS: RANKING OF GROSS INCOME VARIABILITY COEFFICIENTS}

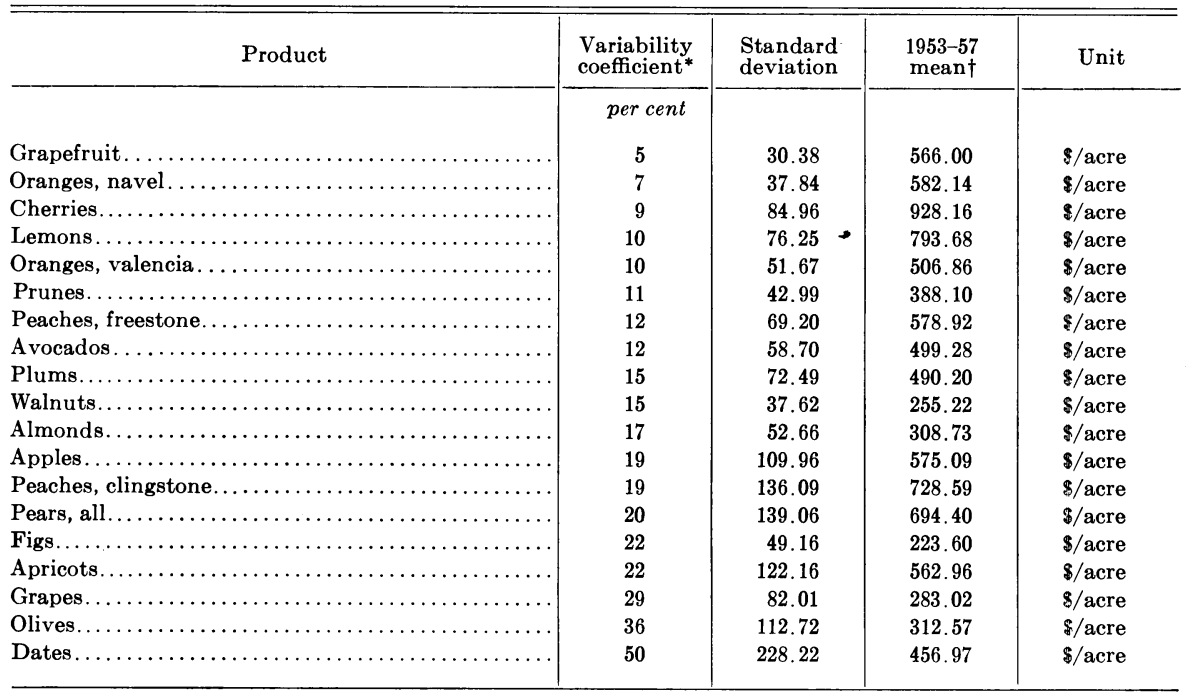

* Variability coefficient $=$ standard deviation (computed from variate difference method) divided by the 1953-57 mean. Computations may not check exactly because data are rounded off for ease in presentation.

† Grapef ruit, lemons, navel and valencia oranges 1952-56 mean. 1957 data not available.

Diversification by adding resources. Suppose a crop farmer diversifies by adding to a fixed acreage of crop $A$ an equal acreage of crop $B$. The income variance of the crop $A$ is represented by $\sigma_{A}{ }^{2}$, the income variance of crop $B$ by $\sigma_{B}{ }^{2}$. When enterprise $B$ is added to $A$ the total income variance $\left(\sigma_{T}{ }^{2}\right)$ becomes:

$$
{\sigma_{T}}^{2}={\sigma_{A}}^{2}+{\sigma_{B}}^{2}+2 r_{A B} \sigma_{A} \sigma_{B}
$$

where $r_{A B}=$ correlation between the incomes of enterprises $A$ and $B$, and $\sigma_{A}$ and $\sigma_{B}$ are the square roots of the income variances for crops $A$ and $B$, respectively. ${ }^{14}$

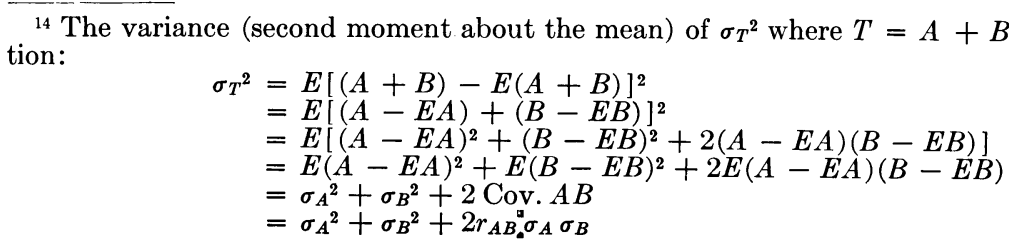


Since net income correlations between crops ordinarily are zero or positive, diversification by adding resources usually increases total income variance. However, total net income also is usually higher. Hence, relative variance (total income variance divided by mean income) may stay the same or decrease even with positive income correlations between crops.

The total variance equation for $n$ enterprises is written as:

$$
\sigma_{T}{ }^{2}=\sum_{\substack{i \\ i=j}}^{n}{\sigma_{i j}}^{2}+2 \sum_{\substack{i j \\ i>j}}^{n} r_{i j} \sigma_{i} \sigma_{j} \quad i, j=1,2, \cdots n
$$

Diversification with redistribution of fixed resources. The second method of diversification is to redistribute a fixed quantity of resources, say land, among additional enterprises. This method is most common for farmers operating with relatively fixed acreage, capital and other resources. In this case, the goal is to reduce uncertainty by dividing a fixed quantity of land among a greater number of enterprises. The equation for the total income variance where one-half of the acres are used in producing crop $A$ and the remainder are diverted to crop $B$ becomes: ${ }^{15}$

$$
\begin{aligned}
& {\sigma_{T}}^{2}=(1 / 2)^{2}{\sigma_{A}}^{2}+(1 / 2)^{2} \sigma_{B}{ }^{2}+2 r_{A B}\left(\sigma_{A} / 2\right)\left(\sigma_{B} / 2\right) \\
& {\sigma_{T}}^{2}=0.25{\sigma_{A}}^{2}+0.25{\sigma_{B}}^{2}+0.50 r_{A B} \sigma_{A} \sigma_{B}
\end{aligned}
$$

In this case, if $0.25 \sigma_{B}^{2}+0.50 r_{A B} \sigma_{A} \sigma_{B}>0.75 \sigma_{A}{ }^{2}$ or, if the ratio

$$
\frac{\sigma_{B}^{2}+2 r_{A B} \sigma_{A} \sigma_{B}}{3 \sigma_{A}{ }^{2}}>1
$$

diversion of one-half the total acres into crop $B$ results in an increase in total income variance; if the ratio equals unity, no change in income variance results; if the ratio is less than unity, income variance is decreased. Thus, opportunities for reducing total income variance by this method of diversification are much greater than by the first method of increasing total resources. With the second method it is often possible to reduce total income variance even in the common case where incomes from crops $A$ and $B$ are positively correlated and the variance of the added crop $\left(\sigma_{B}{ }^{2}\right)$ is greater than the variance of the original crop $\left(\sigma_{A}{ }^{2}\right)$. Also, if the variance of $\operatorname{crop} B$ is less than the variance of crop $A$, total income variance is always reduced, regardless of the income correlation between crops. As noted later, however, the reduction in income variance may be achieved only at a sacrifice in income level.

15 Assume that $q$ is the proportion of total resources devoted to crop A. Then, the variance of $T\left(\sigma_{T^{2}}\right)$ where $T=q A+(1-q) B$ is:

$$
\begin{aligned}
\sigma_{T}^{2} & =\{q A+(1-q) B-E[q A+(1-q) B]\}^{2} \\
& =E[q(A-E A)+(1-q)(B-E B)]^{2} \\
& =q^{2} E(A-E A)^{2}+(1-q)^{2} \mathrm{E}(B-E A)^{2}+2 q(1-q) \mathrm{E}(A-E A)(B-E B) \\
& =q^{2} \sigma_{A}{ }^{2}+(1-q)^{2} \sigma_{B}{ }^{2}+2 q(1-q) \operatorname{Cov} . A B \\
& =q^{2} \sigma_{A}{ }^{2}+(1-q)^{2} \sigma_{B}{ }^{2}+2 q(1-q) r_{A B} \sigma_{A} \sigma B
\end{aligned}
$$

The underlying assumption made here and in the following empirical work is that constant returns to scale exist with respect to each of the crops. 
When the proportion of land resources distributed between two enterprises is unspecified, the total variance equation becomes:

$$
\sigma_{T}{ }^{2}=q^{2} \sigma_{A}{ }^{2}+(1-q)^{2} \sigma_{B}^{2}+2 q(1-q) r_{A B} \sigma_{A} \sigma_{B}
$$

where $q=$ proportion of land resources devoted to $A$ and $1-q=$ proportion of land resources devoted to $B$.

Similarly, the total variance equation for redistributing land resources among $n$ enterprises becomes:

$$
\sigma_{T}{ }^{2}=\sum_{i=1}^{n} q_{i} \sigma_{i}{ }^{2}+2 \sum_{\substack{i, j=1 \\ i>j}}^{n} q_{i} q_{j} r_{i j} \sigma_{i} \sigma_{j}
$$

where $q_{i}(i=1, \ldots n=$ proportion of land resources devoted to enterprise $i$ and $\Sigma q_{i}=1$.

Minimizing absolute variances. Given fixed amounts of land resources, an important problem of diversification is how to estimate the proportion of enterprises to combine in order to obtain minimum absolute variance. Consider first the simplest case where land resources are divided between two enterprises, $A$ and $B$. Equation (6) above gives the absolute variance for an unspecified proportion of land resources devoted to each enterprise. The question is: What value for $q$ provides minimum total variance? Total variance $\left(\sigma_{T}{ }^{2}\right)$ from equation (6) is minimized with respect to $q$ by taking the first derivative of $\sigma_{T}{ }^{2}$ with respect to $q$, setting the result equal to zero and solving for $q$ (see equations 8 and 9). Thus, value of $q$ (the proportion of land resources devoted to $\operatorname{crop} A$ ) which minimizes total variance can be derived, given empirical estimates of ${\sigma_{A}}^{2}, \sigma_{B}{ }^{2}$ and $r_{A B}$. The proportion of land resources remaining for enterprise $B$ is, of course, $1-q$. Determination of the optimum proportions of enterprises for achieving minimum absolute variance becomes more complex where three or more enterprises are involved (as in equation (7)). Variance can be minimized, however, by taking partial derivatives of equation (7) with respect to the appropriate $q$ 's, setting the resulting equations equal to zero and solving simultaneously. For example, with three crops, proportions may be designated $q_{1}, q_{2}$ and $1-q_{1}-q_{2}$. Partial derivatives of equation (7) are taken with respect to $q_{1}$ and $q_{2}$. The two resulting equations are set equal to zero and solved simultaneously for the two unknowns $\left(q_{1}\right.$ and $\left.q_{2}\right)$. The proportion of land resources devoted to the third enterprise is then $1-q_{1}-q_{2}$.

$$
\begin{gathered}
\frac{d \sigma_{T}{ }^{2}}{d q}=2 q \sigma_{A}{ }^{2}-2(1-q){\sigma_{B}}^{2}+2 r_{A B}(1-2 q) \sigma_{A} \sigma_{B}=0 \\
q=\frac{\sigma_{B}{ }^{2}-r_{A B} \sigma_{A} \sigma_{B}}{\sigma_{A}{ }^{2}+\sigma_{B}{ }^{2}-2 r_{A B} \sigma_{A} \sigma_{B}}
\end{gathered}
$$

Minimization of absolute variance with restrictions. In most cases a farmer cannot select combinations of crops solely on the basis of minimum 
variance. Certain crops may be included in cropping systems partly for soil building properties such as nitrogen fixation and addition of organic matter (e.g., alfalfa). Also, some crops alleviate disease problems. For example, alfalfa or barley may be used to avoid nematode build-up in vegetables. Therefore, alternatives are often between two or three "fill-in" crops, given one or two "necessary" crops. For example, in some areas alfalfa is rather automatically included in rotations for three or four years, followed by some combination of barley, potatoes, sugar beets or other crops. Thus, the managerial problem might be to determine the proportions of land to allocate to (say) sugar beets and potatoes in a sequence of alfalfa-alfalfa-alfalfa-sugar beets-potatoes. Equation (10) provides the total variance of a five-crop rotation with fixed proportions of land devoted to three crops (e.g., first, second, and third-year alfalfa) and unspecified proportions for the fourth and fifth crop (e.g., sugar beets and potatoes).$^{16}$

$$
\text { (10) } \begin{aligned}
\sigma_{T}{ }^{2}= & q_{1}^{2} \sigma_{1}{ }^{2} \\
& +q_{2}{ }^{2} \sigma_{2}{ }^{2}+q_{3}{ }^{2} \sigma_{3}{ }^{2}+q_{4}{ }^{2} \sigma_{4}{ }^{2}+\left(k-q_{4}\right)^{2} \sigma_{5}{ }^{2} \\
& +2 q_{1} q_{2} r_{12} \sigma_{1} \sigma_{2}+2 q_{1} q_{3} r_{13} \sigma_{1} \sigma_{3}+2 q_{1} q_{4} r_{14} \sigma_{1} \sigma_{4} \\
& +2 q_{1}\left(k-q_{4}\right) r_{15} \sigma_{1} \sigma_{5}+2 q_{2} q_{3} r_{23} \sigma_{2} \sigma_{3}+2 q_{2} q_{4} r_{24} \sigma_{2} \sigma_{4} \\
& +2 q_{2}\left(k-q_{4}\right) r_{25} \sigma_{2} \sigma_{5}+2 q_{3} q_{4} r_{34} \sigma_{3} \sigma_{4}+2 q_{3}\left(k-q_{4}\right) r_{35} \sigma_{3} \sigma_{5} \\
& +2 q_{4}\left(k-q_{4}\right) r_{45} \sigma_{4} \sigma_{5}
\end{aligned}
$$

where $q_{1}=$ proportion of land resources devoted to crop 1

$q_{2}=$ proportion of land resources devoted to crop 2

$q_{3}=$ proportion of land resources devoted to crop 3

$q_{4}=$ proportion of land resources devoted to crop 4

$k-q_{4}=$ proportion of land resources devoted to crop 5

and $k=1-q_{1}-q_{2}-q_{3}$. Proportions $q_{1}, q_{2}, q_{3}$ and hence $k$ are assumed fixed. The derivative of (10) with respect to $q_{4}$ is:

$$
\begin{aligned}
\frac{d \sigma_{T}{ }^{2}}{d q_{4}}=2 q_{4} \sigma_{4}{ }^{2} & -2\left(k-q_{4}\right) \sigma_{5}{ }^{2}+2 q_{1} r_{14} \sigma_{1} \sigma_{4} \\
& -2 q_{1} r_{15} \sigma_{1} \sigma_{5}+2 q_{2} r_{24} \sigma_{2} \sigma_{4}-2 q_{2} r_{25} \sigma_{2} \sigma_{5} \\
+ & 2 q_{3} r_{34} \sigma_{3} \sigma_{4}-2 q_{3} r_{35} \sigma_{3} \sigma_{5}+2\left(k-q_{4}\right) r_{45} \sigma_{4} \sigma_{5} \\
& -2 q_{4} r_{45} \sigma_{4} \sigma_{5} .
\end{aligned}
$$

\footnotetext{
${ }^{16}$ Although not specified in equation (10) it is assumed that the time sequence of crops will be in the "usual" or "typical" pattern.
} 
Setting (11) equal to zero and solving for $q_{4}$ yields:

$=\frac{k\left(\sigma_{5}{ }^{2}-r_{45} \sigma_{4} \sigma_{5}\right)-q_{1} \sigma_{1}\left(r_{14} \sigma_{4}-r_{15} \sigma_{5}\right)-q_{2} \sigma_{2}\left(r_{24} \sigma_{4}-r_{25} \sigma_{5}\right)-q_{3} \sigma_{3}\left(r_{34} \sigma_{4}-r_{35} \sigma_{5}\right)}{\sigma_{4}^{2}+\sigma_{5}{ }^{2}-2 r_{45} \sigma_{4} \sigma_{5}}$

Empirical estimates of the respective variances and correlations allow estimation of $q_{4}$. The proportion of land resources allocated to enterprise 5 is $k-q_{4}$.

Relative variability. In addition to knowledge about absolute income variance for particular cropping systems the farm manager requires information about the variance in relation to the expected level of income (i.e., relative variability). The coefficient of variability used is defined as the square root of the variance divided by the mean income for $1953-57$ or $\sigma_{T} / \overline{I_{T}}$. Accordingly, using equation (7), the coefficient of variability equation corresponding to the distribution of a fixed quantity of land between $n$ enterprises is:

$$
\frac{\sigma_{T}}{\bar{I}_{T}}=\frac{\left[\sum_{i=1}^{n} q_{i} \sigma_{i}{ }^{2}+2 \sum_{\substack{i=1 \\ i>j}}^{n} q_{i} q_{j} r_{i j} \sigma_{i} \sigma_{j}\right]^{1 / 2}}{\sum_{i=1}^{n} q_{i} \bar{I}_{i}}
$$

Where $q_{i}, q_{j}, \sigma_{i}{ }^{2}$ are as defined previously and $\bar{I}_{i}$ is the mean income, over the period 1953-57, associated with the $i^{\text {th }}$ crop.

\section{Application of Diversification Principles}

Subsequent empirical results are derived from application of the diversificcation principles set forth above. Since cropping patterns differ significantly by area, income variabilities and levels are investigated for a limited number of cropping systems in six agricultural areas of California: (1) Northern Sacramento Valley, (2) Yolo County, (3) Fresno-Madera, (4) Kings-Tulare Lake Basin, (5) Kern County and (6) Imperial Valley. ${ }^{17}$ The Sacramento Valley (including Northern Sacramento Valley and Yolo County) is subject to greater climatic variation than the coastal regions or the San Joaquin Valley. Irrigation is required for most fruit and field crops but not for cereal grains planted to grow during the rainy season in the Sacramento Valley. In the San Joaquin Valley, grain is irrigated. The Northern Sacramento Valley is well adapted to rice and other grain crops. In the Yolo County area, irrigated sugar beets, alfalfa, dry beans, barley, grain sorghum and canning tomatoes are important crops.

\footnotetext{
${ }^{17}$ The Salinas Valley was originally included but later given up because of lack of adequate cost data. The authors believe, however, that a diversification study in the Salinas Valley (given additional time and funds) would be very useful because of the concentration of "high risk" vegetable crops grown in this area. Fruit areas were also excluded, not because of lack of importance but because the authors feel that special methodology must be developed for analyzing diversification systems including these crops.
} 
The San Joaquin Valley (including the Fresno-Madera, Kings-Tulare Lake Basin and Kern County) extends from the Sacramento River Delta southeast to the Tehachapi Mountains. The climate is slightly warmer and the growing season longer than in the Sacramento Valley, allowing a larger variety of crops in the San Joaquin Valley, including crops with longer growing time requirements, like cotton. Within the San Joaquin Valley, areas were delineated primarily on the basis of fairly "typical" cropping systems. ${ }^{18}$ Although fixed crop rotations are seldom followed, general cropping patterns result from localized soil, climatic, and other conditions.

Imperial Valley, characterized by low rainfall and extremely high summer temperatures, depends upon irrigation water from the Colorado River. Crops include vegetables and field crops with primary emphasis on the latter (Shultis, 1951).

Application of the diversification equations (outlined in the preceding section) to cropping systems in each of the six agricultural areas requires estimates of the appropriate variances, standard deviations and correlations. Absolute variance measures and correlation coefficients were derived from historical net income series over the last 20 years (1938-1957).

Due to scarcity of cost data, the income variances derived previously for individual crops were based on gross income (yield per acre $\times$ price). Since the number of crops and cropping systems considered in this section is relatively small, production costs were synthesized to allow use of net income data. Net income per acre is defined as gross income (yield per acre $\times$ annual average price) minus operating costs (excluding depreciation, taxes, and other fixed charges). Individual county yields or weighted average county yields (where more than one county is located in an area) were used for most crops. ${ }^{19}$ Prices were based on state series. Operating costs for each crop in each area were obtained by simple budget and cost studies. Cost series were constructed by adjusting base year costs by the Index of Prices Paid by Farmers for Farm Inputs. Also, where harvesting costs constituted a major cost item, the constructed cost series was adjusted for the level of yield.

For purposes of comparison, the variability measures presented below are based on cropping systems for 560 -acre farms.

Net income correlations between crops. Correlations between the "random elements" of pairs of net income time series were estimated using the variate difference method..$^{20}$ In general, the correlation coefficients obtained by the

${ }^{18}$ Extension Agronomist Milton D. Miller suggested many of the "typical" cropping systems in the six areas studied. The list of cropping combinations is not inclusive but merely illustrative of the many used in each of the areas selected.

${ }^{19}$ For certain crops (e.g., alfalfa) historical county yield data were not available; in these cases state yields were used and adjusted for the average level of yield in each area. That is, the yield variances for alfalfa were based on state series for all areas but the level of yield was adjusted for each area.

so Tintner, op. cit., pp. 117-129. The assumptions made in calculating correlation coeffcients are similar to those made in estimating variances, except that two time series are now being considered. Each time series consists of the mathematical expectation and the random element. Only corresponding elements of both series are correlated. Further, the population variances of the random elements of the two time series are assumed to be $\sigma_{x}{ }^{2}$ and $\sigma_{y}{ }^{2}$, respectively. The population value of their product moment is $\pi$. The product moments of the successive differences of two purely random series should be equal. Thus, if 
variate difference method are much lower than those of the original series. The actual net incomes of crops tend to be highly correlated because the major economic influences (inflation, price cycles, wars, level of technology, etc.) affect most enterprises similarly. Which is more meaningful for decision-making - the correlation between (1) the original series or (2) the random elements? In the "no knowledge" case mentioned previously in which all deviations from the long run mean are considered random or unpredictable, the relevant correlation is between the original series. ${ }^{21}$ In practice, however, farmers are generally aware of long run trends and hence are constantly revising plans in light of new technology and changing demands and price relationships. Here the correlation of the random elements appears more reasonable. At a given point in time the farmer is aware of general relative levels of income from various enterprises. He wants a measure of the relationship between random year-to-year changes in net income for various crops. For example, if two enterprises have a strong negative correlation between their random components they might make an excellent diversification prospect for a particular year, even though the correlation between the original series is strongly positive.

Net income correlation coefficients ranged from -0.38 for alfalfa-sugar beets in Yolo County to 0.63 for alfalfa-barley in Imperial County (Table 10). A positive net income correlation between alfalfa and barley appears reasonable; since both are livestock feeds their respective prices would tend to fluctuate together. In general, crops with positive correlations are less desirable income stabilizing alternatives than crops with zero or negative correlations. However, negative correlations (around -0.30) were estimated between alfalfa and cotton in three areas of the San Joaquin Valley. Year-toyear fluctuations in net incomes per acre for alfalfa and cotton tend to move in opposite directions; 12 of the 20 years observed followed this pattern. Although correlation does not necessarily imply causality, a partial explanation may be that alfalfa acreage, and hence alfalfa production, ordinarily is increased as cotton acreage is restricted.

In the Northern Sacramento Valley, positive net income correlations (about 0.40) were estimated between rice and wheat and between rice and barley. Since the absolute income variances of wheat and barley are about

the nonrandom element or mathematical expectation is essentially eliminated in the $\mathrm{k}_{\mathrm{o}}$ th difference, the following relationship holds:

$$
P_{k_{\mathrm{o}}}=P_{k_{0+1}}=P_{k_{0+2}} \cdots,
$$

where $P_{k}$ denotes the empirical approximation to the product moment of two series calculated from the $k^{\text {th }}$ differences. Various procedures are available for testing statistically the above equality. The correlation coefficient $r_{k}$ is then:

$$
r_{k}=P_{k} /\left[V_{k}(x) V_{k}(y)\right]^{1 / 2},
$$

where $V_{k}(x)$ and $V_{k}(y)$ are approximations of $\sigma_{x}^{2}$ and $\sigma_{y}^{2}$ respectively.

${ }^{21}$ Since derivation of the variance of an enterprise combination requires estimates of both individual enterprise variances and the covariance between enterprises, mathematical consistency requires both variance and covariances to be based either on the original series or on the random elements of the series. In other words, it is inconsistent to combine "random" variances and "actual". correlations, or vice versa. 
equal, similar reductions in income variance could be expected from the diversion of rice acreage to either wheat or barley.

High positive income correlations (around 0.60) were obtained in the Yolo County area ${ }^{22}$ between tomatoes (both leased and owner-operator) and alfalfa. On the other hand, the income correlations between tomatoes and barley were low (about 0.16). A partial explanation may be that alfalfa and tomatoes are both irrigated crops while barley (in Yolo County) is primarily

TABLE 10

NET INCOME CORRELATION COEFFICIENTS BETWEEN SELECTED CROP COMBINATIONS IN MAJOR FARMING AREAS OF CALIFORNIA*

\begin{tabular}{|c|c|c|c|c|c|c|}
\hline \multirow[b]{2}{*}{ Crop combination $\dagger$} & \multicolumn{6}{|c|}{ Area } \\
\hline & $\begin{array}{c}\text { Northern } \\
\text { Sacra- } \\
\text { mento } \\
\text { Valley }\end{array}$ & Yolo & $\begin{array}{l}\text { Fresno- } \\
\text { Madera }\end{array}$ & $\begin{array}{c}\text { Kings- } \\
\text { Tulare } \\
\text { Lake }\end{array}$ & Kern & $\underset{\text { Valley }}{\text { Imperial }}$ \\
\hline
\end{tabular}

* These correlation coefficients are between the "random" components of pairs of crops. Calculations are based on 1938-57 data, except for sugar beets (1938-56).

$\dagger$ Tomatoes (owner-operator) refers to the situation where the farm owner supervises the tomato operation; tomatoes (leased) refers to the situation where the owner rents the land to a tenant forvises the tomato operation; tomatoes in return for 17 per cent of the gross income. In both cases the net income measures relate to the owner.

a dryland crop. Also, in Yolo County, the net income correlations of sugar beets-tomatoes and sugar beets-barley are virtually zero. Governmental controls which reduce income fluctuations on sugar beets may explain these low correlations. Observations might also be made regarding correlations between crops in other areas.

Variability with crop diversification. In this section only one type of diversification is considered: The case where the manager has a fixed quantity

${ }^{22}$ Variability measures for two types of tomato enterprises were estimated for Yolo County: (1) Tomatoes (leased) and (2) tomatoes (owner-operator). Tomatoes (leased) refers to the rather common practice in which a specialized tomato producer leases land from a land owner for the purpose of tomato production. In this study the level and variability of net income to the land owner is examined; the land owner is assumed to receive 17 per cent of the gross return from tomatoes. Tomatoes (owner-operated) refers to the practice where the land owner himself grows the tomatoes. 
of land which ean be diverted to one or more crops as a means of lessening income variability. Table 11 presents variability measures and expected level of net income in each area for a limited number of cropping patterns. Variability measures in Table 11 are presented in terms of 560 acres divided equally among the respective crops.

Northern Sacramento Valley. In the Northern Sacramento Valley as land is shifted from rice alone (560 acres of rice) to a cropping pattern of R-R-R-B (420 acres of rice and 140 acres of barley) the standard deviation of net income decreases from $\$ 13,328$ to $\$ 10,696$ (Table 11). However, barley is a lower income crop than rice, resulting in a decline from $\$ 48,306$ to $\$ 39,154$ in the mean net income associated with the rice-barley combination. The corresponding variability coefficient remains essentially unchanged. Similarly, the diversion of 140 acres of rice to wheat results in (1) a reduction in the expected mean net income to $\$ 39,715$ (2) a reduction in absolute income variability (standard deviation) to $\$ 10,304$ and (3) a small reduction in the relative variability coefficient from 28 to 26 per cent. Diverting the 140 acres to summer fallow R-R-R-F) rather than wheat or barley results in a considerable reduction in mean income (compared to rice alone) and a negligible increase in the relative variability coefficient from 28 to 29 per cent. Rotation of rice land to dryfarmed grain or summer fallow is generally considered a necessary control for weeds. From the results shown, barley or wheat allows about the same reduction in income variance as summer fallow, but with less reduction in net income.

Yolo County. Variability estimates for four different crop combinations are derived for the Yolo County area. Alfalfa (3 years) was considered a mainstay in all rotations. ${ }^{23}$ Some of the cash crops commonly grown with alfalfa are sugar beets, tomatoes, and barley. In Yolo County, tomatoes (owner-operator) has the greatest absolute net income variability $(\$ 16,106)$, while dryland barley has the lowest absolute net income variability $(\$ 3,220)$. Relative income variability for individual crops (as indicated by the variability coefficient) is greatest for alfalfa and sugar beets (33 and 25 per cent, respectively). Combinations of these individual crops resulted, in most cases, in a reduction in absolute and relative income variability. For example, the cropping system A-A-A-SB-T-SB shows an absolute income variance of $\$ 5,992$ and a variability coefficient of 15 per cent. This particular combination greatly reduced income variability because alfalfa and sugar beets are negatively correlated $(-0.38)$ and because tomatoes and sugar beets have a low income correlation (0.01).

The A-A-A-T-SB-B combination results in a standard deviation of $\$ 6,530$. The same rotation, except with tomatoes (leased) substituted for tomatoes (owner-operator), showed a considerably lower absolute income variability $(\$ 4,872)$. However, net income is proportionately reduced so that relative variabilities from the two crop combinations are about equal (18 and 17 per cent, respectively). The A-A-A-SB-B-B combination exhibits the lowest absolute variability of the crop combination considered in Yolo County. Yet, because a relatively large proportion of the land in this combination is de-

\footnotetext{
${ }^{23}$ An alfalfa field is usually left in from 3 to 5 years. Recently, the tendency has been to shorten the rotation to 3 or 4 years. Hence, 3 years was selected for the following examples.
} 
TABLE 11

NET INCOME VARIABILITY COMPARISONS BETWEEN SELECTED CROPS AND CROP COMBINATIONS IN SIX AREAS OF CALIFORNIA

(Assuming a 560-acre farm)

\begin{tabular}{|c|c|c|c|}
\hline Crop combination* & $\begin{array}{c}\text { Mean } \\
\text { net income } \\
1953-57 \dagger \\
\text { (dollars) }\end{array}$ & $\begin{array}{c}\text { Standard } \\
\text { deviation } \ddagger \\
\text { (dollars) }\end{array}$ & $\begin{array}{c}\text { Variability } \\
\text { coefficient } \$ \\
\text { (per cent) }\end{array}$ \\
\hline$\cdot$ & \multicolumn{3}{|c|}{ Northern Sacramento Valley } \\
\hline & \multicolumn{3}{|c|}{ Yolo County } \\
\hline 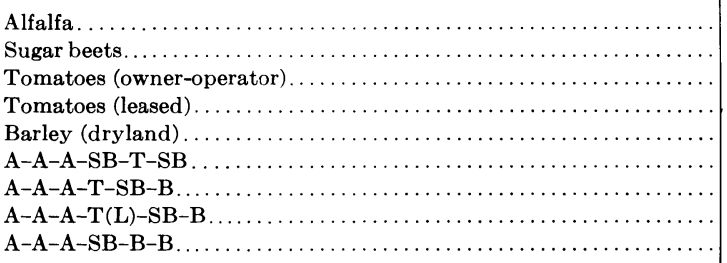 & $\begin{array}{l}28,095 \\
38,931 \\
82,337 \\
36,137 \\
13,653 \\
40.891 \\
36,982 \\
29,731 \\
25,172\end{array}$ & $\begin{array}{r}9,150 \\
9,766 \\
16,106 \\
3,304 \\
3,220 \\
5,992 \\
6,530 \\
4,872 \\
4,833\end{array}$ & $\begin{array}{r}33 \\
25 \\
20 \\
9 \\
24 \\
15 \\
18 \\
17 \\
25\end{array}$ \\
\hline 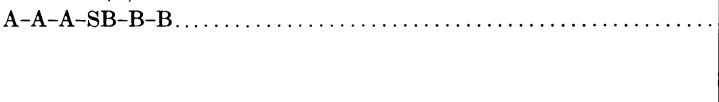 & \multicolumn{3}{|c|}{ Fresno-Madera area } \\
\hline & \multicolumn{3}{|c|}{ Kings-Tulare Lake basin } \\
\hline 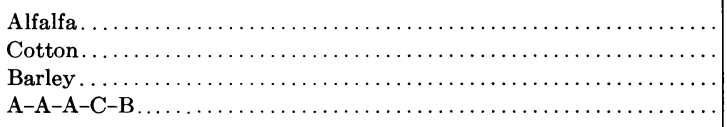 & $\begin{array}{r}28,991 \\
85,999 \\
8,837 \\
36,361\end{array}$ & $\begin{array}{r}10,231 \\
24,976 \\
3,702 \\
7,006\end{array}$ & $\begin{array}{l}35 \\
29 \\
42 \\
19\end{array}$ \\
\hline 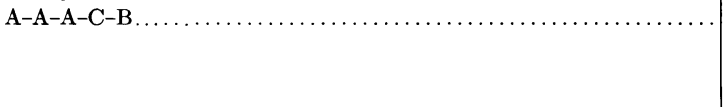 & \multicolumn{3}{|c|}{ Kern County } \\
\hline 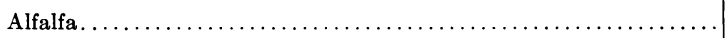 & 31,018 & 11,217 & 36 \\
\hline 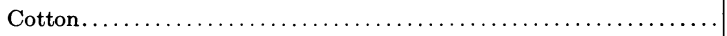 & 105,353 & 29,120 & 28 \\
\hline 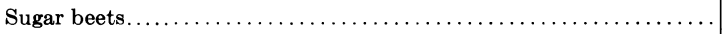 & 27,160 & 19,029 & 70 \\
\hline 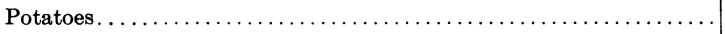 & 89,510 & 121,968 & 136 \\
\hline 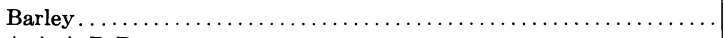 & 8,897 & 3,712 & 42 \\
\hline 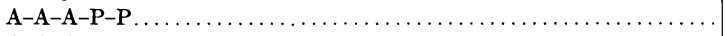 & 54,415 & 50,523 & 93 \\
\hline 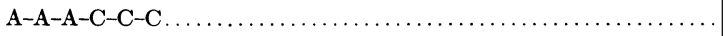 & 68,186 & 14,011 & 21 \\
\hline 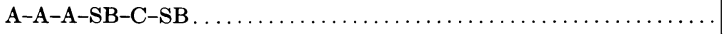 & 42,381 & 11,256 & 27 \\
\hline 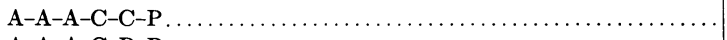 & 65,492 & 22,008 & 35 \\
\hline 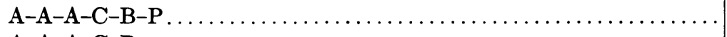 & 50,137 & 21,840 & 44 \\
\hline 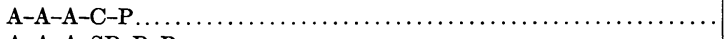 & 57,585 & 25,833 & 45 \\
\hline 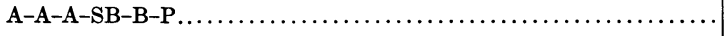 & 36,842 & 23,660 & 64 \\
\hline
\end{tabular}


TABLE 11-Concluded

\begin{tabular}{|c|c|c|c|}
\hline Crop combination* & $\begin{array}{c}\text { Mean } \\
\text { net income } \\
1953-57 \dagger \\
\text { (dollars) }\end{array}$ & $\begin{array}{c}\text { Standard } \\
\text { deviation } \ddagger \\
\text { (dollars) }\end{array}$ & $\begin{array}{l}\text { Variability } \\
\text { coefficient } \$ \\
\text { (per cent) }\end{array}$ \\
\hline & \multicolumn{3}{|c|}{ Imperial Valley } \\
\hline Alfalfa. & 34,989 & 11,396 & 33 \\
\hline Cotton.. & 94,494 & 20,972 & 22 \\
\hline Sugar beets. & 53,502 & 9,397 & 18 \\
\hline Barley ................. & 15,450 & 2,615 & 17 \\
\hline $\mathrm{A}-\mathrm{A}-\mathrm{A}-\mathrm{C}-\mathrm{C}-\mathrm{SB} \ldots$ & 48,681 & 9,850 & 20 \\
\hline A-A-A-C-B-SB . . & 35,638 & 7,683 & 22 \\
\hline$A-A-A-C-C-C$. & 55,647 & 12,549 & 23 \\
\hline $\mathrm{A}-\mathrm{A}-\mathrm{A}-\mathrm{C}-\mathrm{C}-\mathrm{B}$ & 42,207 & 9,862 & 23 \\
\hline
\end{tabular}

* Assumes equal proportions of the 560 acre farm devoted to each crop in the crop combination. For example, "Rice" refers to 560 acres of rice alone; $R-R-R-B$ refers to 420 acres of rice and 140 acres of barley. Symbols are defined as: $\mathrm{A}=$ alfalfa, $\mathrm{B}=$ barley, $\mathrm{C}=$ cotton, $\mathrm{Ca}=$ cantaloupes, $\mathrm{SB}=$ sugar beets, $\mathrm{R}=$ rice, $\mathrm{W}=$ wheat, $\mathrm{F}=$ fallow, $\mathrm{T}=$ tomatoes (owner handles complete operation) $\mathrm{T}(\mathrm{L}) \stackrel{\text { tomatoes (owner leases land in return for }}{=}$ 17 per cent of gross income), and $P=$ potatoes.

$\dagger$ Net income refers to gross income minus operating costs (excluding depreciation, taxes and interest on investment). The years 1952-56 were used for sugar beets, $1953-1957$ for all other crops.

$\ddagger$ Standard deviation is the square root of the estimated variance (computed from variate difference method) for the respective crop combinations.

$\S$ The variability coefficient is the ratio of the standard deviation (computed from variate difference method) (column 2) to the mean net income (column 1), multiplied by 100.

voted to low income barley, the reduction in income variability is achieved at a sizeable sacrifice in net income. Consequently, the relative variability for this combination is the highest (25 per cent) of those considered in Yolo County.

Tables 12 and 13 show that variability measures for diversified cropping systems change as the proportions of land devoted to two crops are varied. Specifically, Table 12 shows that the absolute and relative income variability both increase, after a slight reduction, as land is diverted from sugar beets to tomatoes (leased) in Yolo County. (The rotation also included 336 acres of alfalfa divided equally among first, second, and third-year stands.) The absolute variability (standard deviation) increases from $\$ 5,477$ where the entire 224 acres is allocated to sugar beets, to $\$ 6,334$ where the same acreage is leased out for tomatoes. This particular case indicates that not only the income variance of individual crops should be known, but also whether or not year-to-year net income from specified crops fluctuates in the same direction. This relation is measured by the correlation coefficient and applied in the diversification equation as part of the covariance term (see equation 7 ). The absolute income variance of sugar beets is much larger than that estimated for tomatoes (leased). Therefore, it would appear that diverting land from sugar beets to tomatoes would certainly lessen total income variance. Table 12 shows that the income standard deviation declines, as expected, up to the point where 45 acres have been diverted to tomatoes (leased) from the 224 acres originally in sugar beets. But as additional acres (beyond 45 acres) are diverted to tomatoes, the total income standard deviation reverses direction and increases slightly. Alfalfa and sugar beets incomes are negatively correlated while the converse is true for alfalfa and tomatoes (leased); these correlation coefficients are reflected in the covariance term which is an important influencing factor in calculating total variance. 
Table 13 shows that diversion of land from barley to tomatoes (leased) with a fixed acreage of alfalfa and sugar beets results in a slight increase in absolute variability (from $\$ 4,872$ to $\$ 5,029$ ). However, since tomatoes (leased) yield a higher net cash return than barley with only a slightly higher absolute net income variability, relative variability declines from 19 to 15 per cent.

TABLE 12

NET INCOME VARIABILITY IN YOLO COUNTY WITH 336 ACRES OF ALFALFA AND VARIABLE PROPORTIONS OF 224 ACRES ALLOCATED TO TOMATOES (LEASED) AND SUGAR BEETS*

\begin{tabular}{c|c|c|c|c}
\hline \multicolumn{2}{c|}{ Acres used for } & $\begin{array}{c}\text { Mean net income } \\
(1953-57) \dagger\end{array}$ & $\begin{array}{c}\text { Standard } \\
\text { deviation }\end{array}$ & $\begin{array}{c}\text { Variability } \\
\text { coefficient }\end{array}$ \\
\cline { 1 - 2 } Tomatoes (leased) & Sugar beets & dollars & dollars & per cent \\
\cline { 1 - 2 } & & 32,430 & 5,477 & 17 \\
22 & 224 & 32,318 & 5,432 & 17 \\
45 & 202 & 32,206 & 5,421 & 17 \\
67 & 179 & 32,094 & 5,438 & 17 \\
90 & 157 & 31,982 & 5,477 & 18 \\
112 & 134 & 31,870 & 5,561 & 18 \\
134 & 112 & 31,758 & 5,662 & 19 \\
157 & 90 & 31,646 & 5,796 & 20 \\
179 & 67 & 31,534 & 5,953 & 20 \\
202 & 45 & 31,422 & 6,132 & 6,334 \\
\end{tabular}

* Tomatoes (leased) refers to land leased out to tenant for growing tomatoes. The net income to the owner is 17 per cent of the gross income received by the tenant. The above calculations are from the standpoint of net income to the owner.

+ Net income refers to gross income minus operating costs (excluding depreciation, taxes, and interest on investment). Means were based on years 1952-56 for sugar beets; $1953-57$ for all other crops.

Standard deviation is the square root of the estimated variance (computed from variate difference method) for the respective crop combinations.

$\$$ The variability coefficient is the ratio of the standard deviation (computed from variate difference method) (column 2) divided by the mean income (column 1), multiplied by 100.

Fresno-Madera Area. Table 11 summarizes the variability estimates for alfalfa and three cash crops, both individually and in various crop combinations. Relative income variability (as measured by the variability coefficient) for alfalfa in the Fresno-Madera area is comparably high, mainly because of low relative yield as reflected in the mean net income. Absolute income variability (as measured by the standard deviation) for alfalfa in this area is comparable to other areas. Cantaloupes is, as would be expected, a high "risk" crop (both absolute and relative) as well as a high value crop; the inclusion of cantaloupes into most cropping systems tends to increase both income levels and income variability. For example, the diversion of 140 acres of the total 560 acres from alfalfa to cantaloupes (the A-A-A-Ca combination) increases the net income standard deviation from $\$ 9,358$ to $\$ 15,786$ but, at the same time, the expected net income is increased from $\$ 22,462$ to $\$ 35,358$. The result is a small increase in the relative variability coefficient from 42 to 45 per cent. Similarly, a comparison of A-A-A-C-C-SB with A-A-A-C-C-Ca indicates that cantaloupes rather than sugar beets increases both the level and variability of net income. In this case, the relative variability increases from 23 to 28 per cent with cantaloupes. Comparison of A-A-A-C-SB-Ca and A-A-A-C-C-Ca indicates that substitution of cotton for sugar beets increases 
the level and variability about proportionately, leaving relative variability unchanged (28 per cent).

Kings-Tulare Lake Basin. Table 11 shows that barley has the lowest absolute income variability $(\$ 3,702)$ for the single crops studied in the KingsTulare Lake Basin area. Barley, however, was also the lowest value crop (mean income of $\$ 8,837$ ) and showed the greatest relative variability (42 per cent). Conversely, cotton exhibited the greatest absolute income variation (a standard deviation of $\$ 24,976$ ), but the lowest relative variability (a

TABLE 13

NET INCOME VARIABILITY ON 560-ACRE FARMS IN YOLO COUNTY WITH 280 ACRES OF ALFALFA, 93 ACRES OF SUGAR BEETS AND VARIABLE PROPORTIONS OF 187 ACRES ALLOCATED TO TOMATOES (LEASED) AND BARLEY*

\begin{tabular}{c|c|c|c|c}
\hline \hline \multicolumn{2}{c|}{ Acres used for } & Mean net income \\
$(1953-1957) \dagger$ & Standard \\
Tomatoes (leased) & Barley & dollars & dollars & $\begin{array}{c}\text { Variability } \\
\text { coefficient }\end{array}$ \\
\cline { 1 - 3 } & & & & per cent \\
0 & 187 & 25,088 & 4,872 & 19 \\
19 & 168 & 25,833 & 4,872 & 19 \\
37 & 150 & 26,583 & 4,873 & 18 \\
56 & 131 & 27,334 & 4,872 & 18 \\
95 & 112 & 28,084 & 4,883 & 17 \\
112 & 94 & 28,834 & 4,900 & 17 \\
131 & 75 & 29,585 & 4,917 & 16 \\
150 & 56 & 30,335 & 4,939 & 16 \\
168 & 37 & 31,086 & 4,962 & 16 \\
187 & 19 & 31,830 & 4,995 & 15 \\
\hline
\end{tabular}

* Tomatoes (leased) refers to land leased out to tenant for growing tomatoes. The net income to the owner is 17 per cent of the gross income received by the tenant. The above calculations are from the standpoint of net income to the owner.

$\dagger$ Net income refers to gross income minus operating costs (excluding depreciation, taxes and interest on investment). Means were based on years 1952-1956 for sugar beets; $1953-57$ for all other crops.

\$ Standard deviation is the square root of the estimated variance (computed from variate difference method) for the respective crop combinations.

$\$$ The variability coefficient is the ratio of the standard deviation (computed from variate difference method) (column 2) divided by the mean income (column 1), multiplied by 100.

variability of coefficient of 29 per cent). The only cropping pattern analyzed in this area was three years of alfalfa followed by cotton and barley. Diversion of 280 acres of alfalfa to 140 acres each of cotton and barley reduces both the absolute and relative income variability from that shown for alfalfa grown alone, yet the level of income is increased from $\$ 28,991$ to $\$ 36,361$.

Kern County. Crop production in Kern County generally shows greater income variability than in the other five areas. A large part of the sugar beet income variability is related directly to an unstable yield record. Also, average net income from sugar beets is substantially lower in Kern County than in most other areas, resulting in a high variability coefficient ( 70 per cent). As previous estimates indicate, early potatoes are the most "risky" crop; the standard deviation is $\$ 121,968$, relative to a mean net income of $\$ 89,510$. Thus, the corresponding variability coefficient is 136 per cent. The high net income variability of early potatoes in Kern County is dramatized further by the fact that net income per acre over the last five years has varied from 
$-\$ 105$ to $\$ 677$. Therefore, the addition of potatoes to any rotation system will increase both the absolute and relative variability. For example, the Kern County cropping system with the greatest variability is A-A-A-P-P. Here the income standard deviation is $\$ 50,523$, and the mean net income (1953-1957) $\$ 54,415$; the resulting variability coefficient is 93 per cent. Thus, diversion of 280 acres from alfalfa to potatoes increases the net income standard deviation from $\$ 11,217$ to $\$ 50,523$; correspondingly the mean net income is increased from $\$ 31,018$ to $\$ 54,415$. Similar comparisons can be made with other crops. In general, however, the addition of cotton to the rotation tends to decrease the relative variability while the addition of barley tends to decrease the absolute variability.

TABLE 14

NET INCOME LEVELS AND VARIABILITY ON 560-ACRE FARMS IN KERN COUNTY WITH 280 ACRES OF ALFALFA AND VARIABLE PROPORTIONS OF 224 ACRES ALLOCATED TO BARLEY AND EARLY POTATOES

\begin{tabular}{c|c|c|c|c}
\hline \hline \multicolumn{2}{c|}{ Acres used for } & $\begin{array}{c}\text { Mean net income } \\
1953-57^{*}\end{array}$ & $\begin{array}{c}\text { Standard } \\
\text { deviation } \dagger\end{array}$ & $\begin{array}{c}\text { Variability } \\
\text { coefficient }\end{array}$ \\
\hline Barley & Potatoes & dollars & dollars & per cent \\
& & & & 107 \\
22 & 224 & 47,359 & 50,540 & 104 \\
45 & 202 & 44,128 & 45,769 & 100 \\
67 & 179 & 40,902 & 41,003 & 96 \\
90 & 157 & 37,677 & 36,266 & 92 \\
112 & 134 & 34,446 & 31,545 & 86 \\
134 & 112 & 31,226 & 26,874 & 80 \\
157 & 90 & 27,994 & 22,277 & 72 \\
179 & 67 & 24,769 & 17,791 & 63 \\
202 & 45 & 21,543 & 13,558 & 54 \\
224 & 22 & 18,312 & 9,890 & 51 \\
\hline
\end{tabular}

* Net income refers to gross income minus operating costs (excluding depreciation, taxes and interest on investment). The years 1952-56 were used for sugar beets, 1953-1957 for all other crops.

$\dagger$ Standard deviation is the square root of the estimated variance (computed from variate difference method) for the respective crop combinations.

$\ddagger$ The variability coefficient is the ratio of the standard deviation (computed from variate difference method) (column 2) to the mean net income (column 1), multiplied by 100.

Further comparisons of income stability and income levels in Kern County are shown in Tables 14 and 15 . Table 14 shows that as acres are diverted from potatoes to barley the result is (1) a substantial lowering of the mean net income from $\$ 47,359$ to $\$ 15,086$, (2) a decrease in the income standard deviation from $\$ 50,540$ to $\$ 7,650$ and (3) a decrease in the relative variability coefficient from 107 to 51 per cent.

Similar results are shown in Table 15, where income stability and levels are examined as acres are diverted from potatoes to sugar beets. In both of the above cases, 60 per cent ( 336 acres) of the land is allocated to alfalfa (112 acres each of first, second, and third-year stands). Variability measures are, of course, based on the total cropping patterns.

Imperial Valley. Table 11 indicates that individual Imperial Valley alfalfa, cotton, sugar beet and barley crops are relatively stable. As with most of the other areas, cotton shows the greatest absolute income variability 
but, since it is a high value crop, relative variability is low (22 per cent). Barley has the lowest absolute income variability $(\$ 2,615)$, and also the lowest variability coefficient (17 per cent). Of the cropping patterns selected (assuming equal acreages in each crop) no substantial differences in relative net income variability were observed. Also the magnitudes of the variability coefficients were low, ranging from 20 to 23 per cent. The addition of some "high risk" vegetable crops into these cropping systems would substantially alter this situation.

TABLE 15

NET INCOME LEVELS AND VARIABILITY ON 560-ACRE FARMS IN KERN COUNTY WITH 336 ACRES OF ALFALFA AND VARIABLE PROPORTIONS OF 224 ACRES ALLOCATED TO SUGAR BEETS AND EARLY POTATOES

\begin{tabular}{c|c|c|c|c}
\hline \hline \multicolumn{2}{c|}{ Acres used for } & $\begin{array}{c}\text { Mean net income } \\
(1953-57)^{*}\end{array}$ & $\begin{array}{c}\text { Standard } \\
\text { deviation } \dagger\end{array}$ & $\begin{array}{c}\text { Variability } \\
\text { coefficient } \ddagger\end{array}$ \\
\cline { 1 - 3 } Sugar beets & Potatoes & dollars & dollars & per cent \\
& & 47,359 & 50,540 & 107 \\
22 & 224 & 44,862 & 45,937 & 102 \\
45 & 202 & 42,370 & 41,373 & 98 \\
67 & 179 & 39,878 & 36,854 & 87 \\
90 & 157 & 37,380 & 32,407 & 80 \\
112 & 134 & 34,888 & 28,067 & 74 \\
134 & 112 & 32,390 & 23,884 & 67 \\
157 & 90 & 29,898 & 19,970 & 60 \\
179 & 67 & 27,406 & 16,498 & 55 \\
202 & 45 & 24,909 & 13,821 & 55 \\
224 & 22 & 22,417 & 12,466 & 50 \\
\hline
\end{tabular}

* Net income refers to gross income minus operating costs (excluding depreciation, taxes and interest on investment). The years $1952-56$ were used for sugar beets, 1953-1957 for all other crops.

t Standard deviation is the square root of the estimated variance (computed from variate difference method) for the respective crop combinations.

t The variability coefficient is the ratio of the standard deviation (computed from variate difference method) (column 2) to the mean net income (column 1), multiplied by 100 .

Table 16, the comparison of income stability and levels as acres are diverted from sugar beets to cotton, shows (1) an increase in the mean net income from $\$ 42,398$ to $\$ 58,794$, and (2) an increase in the absolute variability from $\$ 7,874$ to $\$ 11,480$. Insignificant changes resulted in the variability coefficient.

In similar situations where acres are diverted from barley to sugar beets (Table 17) small increases in absolute variability accompanied by a substantial increase in expected income gives the net result of a decrease in relative variability. The variability coefficient decreases from 28 per cent with 336 acres of alfalfa and 224 acres of barley, to 19 per cent with the same acreage in alfalfa and 224 acres of sugar beets.

\section{ACKNOWLEDGMENTS}

Most of the data used in this report was provided by the California Crop and Livestock Reporting Service. The authors gratefully acknowledge the aid of personnel in this agency who made available certain unpublished county data in addition to published materials. Data also were obtained 
TABLE 16

NET INCOME LEVELS AND VARIABILITY ON 560-ACRE FARMS IN IMPERIAL COUNTY WITH 336 ACRES OF ALFALFA AND VARIABLE PROPORTIONS OF 224 ACRES ALLOCATED TO COTTON AND SUGAR BEETS

\begin{tabular}{c|c|c|c|c}
\hline \hline \multicolumn{2}{c|}{ Acres used for } & $\begin{array}{c}\text { Mean net income } \\
(1953-57)^{*}\end{array}$ & $\begin{array}{c}\text { Standard } \\
\text { deviation } \dagger\end{array}$ & $\begin{array}{c}\text { Variability } \\
\text { coefficient }\end{array}$ \\
\hline Cotton & Sugar beets & dollars & dollars & 19 \\
& & & 7,874 & 18 \\
22 & 224 & 42,398 & 7,879 & 17 \\
45 & 202 & 44,033 & 7,986 & 17 \\
67 & 179 & 45,674 & 8,176 & 17 \\
90 & 157 & 47,314 & 8,462 & 18 \\
112 & 134 & 48,955 & 8,820 & 18 \\
134 & 112 & 50,596 & 9,251 & 18 \\
157 & 90 & 52,237 & 9,738 & 19 \\
179 & 67 & 53,872 & 10,242 & 20 \\
202 & 45 & 55,513 & 10,858 & 11,480 \\
224 & 22 & 57,154 & & \\
\hline
\end{tabular}

* Net income refers to gross income minus operating costs (excluding depreciation, taxes and interest on investment). The years $1952-56$ were used for sugar beets, 1953-1957 for all other crops.

t Standard deviation is the square root of the estimated variance (computed from variate difference method) for the respective crop combinations.

The variability coefficient is the ratio of the standard deviation (computed from variate difference method) (column 2) to the mean net income (column 1), multiplied by 100 .

TABLE 17

NET INCOME LEVELS AND VARIABILITY ON 560-ACRE FARMS IN IMPERIAL COUNTY WITH 336 ACRES OF ALFALFA AND VARIABLE PROPORTIONS OF 224 ACRES ALLOCATED TO SUGAR BEETS AND BARLEY

\begin{tabular}{c|c|c|c|c}
\hline \hline \multicolumn{2}{c|}{ Acres used for } & $\begin{array}{c}\text { Mean net income } \\
(1953-57)^{*}\end{array}$ & $\begin{array}{c}\text { Standard } \\
\text { deviation } \dagger\end{array}$ & $\begin{array}{c}\text { Variability } \\
\text { coefficient }\end{array}$ \\
\cline { 1 - 3 } Sugar beets & Barley & dollars & dollars & per cent \\
& & & & 28 \\
22 & 224 & 27,177 & 7,577 & 26 \\
45 & 202 & 28,694 & 7,526 & 25 \\
67 & 179 & 30,218 & 7,493 & 22 \\
90 & 157 & 31,741 & 7,476 & 22 \\
112 & 134 & 33,264 & 7,476 & 21 \\
134 & 112 & 34,787 & 7,498 & 20 \\
157 & 90 & 36,305 & 7,538 & 19 \\
179 & 67 & 37,828 & 7,594 & 19 \\
202 & 45 & 39,351 & 7,672 & 19 \\
224 & 22 & 40,869 & 7,767 & 7,874 \\
\hline
\end{tabular}

* Net income refers to gross income minus operating costs (excluding depreciation, taxes and interest on investment). The years 1952-56 were used for sugar beets, 1953-57 for all other crops.

Standard deviation is the square root of the estimated variance (computed from variate difference method) for the respective crop combinations.

$\ddagger$ The variability coefficient is the ratio of the standard deviation (computed from variate difference method) (column 2) to the mean net income (column 1), multiplied by 100. 
from the Yolo County Agricultural Stabilization and Conservation Office. Finally, the authors wish to thank C. O. McCorkle, Jr., G. M. Kuznets, E. C. Voorhies, T. R. Hedges and S. S. Hoos of the California Agricultural Experiment Station, and M. D. Miller, K. R. Farrell and G. A. Rowe of the California Agricultural Extension Service for assistance at various stages of the project and for reviewing a preliminary draft of the manuscript. The authors accept full responsibility for any errors of fact or interpretation.

\section{APPENDIX A}

Tables A-1, A-2 and A-3 present variability estimates where the series of historical data are divided into two sub-time periods (1918-1937 and 19381957). The sub-period analysis serves two purposes: (1) to compare absolute variances between time periods and (2) to compare relative variability between time periods.

Bartlett's test was used as a criterion for deciding if the absolute variance changed significantly from the first period to the second; i.e., whether variance is homogeneous with respect to time. If the calculated value of chisquare exceeded the tabular value at the five per cent level, then the observed difference in variance between sub-time periods was judged sufficiently large to have occurred by chance only 5 times in 100 . Where a significant difference was obtained (denoted by asterisk superscripts on chi-square values in Tables A-1, A-2 and A-3) the standard deviation ( $\sqrt{\text { variance }}$ ) for the second period was taken as the best estimate of future standard deviation. Thus, in Tables 1 through 9 in the text, the "whole period" standard deviation was used if the chi-square value was not significant; the "second period" standard deviation was used if the chi-square value was significant.

No formal test was used to determine if relative variability (as measured by coefficient of random variability, Tables A-1, A-2 and A-3) changed significantly over time. Only general directions of change are noted. In some cases absolute variance increased significantly over time, yet the coefficient of variability declined. In other words, the standard deviation increased proportionally less than the mean. ${ }^{24}$

Table A-1 presents the two-period results for field crops. Other things being equal, as the mean level of yield, price or gross income increases, absolute variance also increases. This conclusion follows because in general large quantities tend to vary more absolutely than small quantities. Thus, it is interesting that both barley and wheat yields have decreased in absolute variance over time while average yields have increased. The shift over time from mainly dry-land to more irrigated barley and wheat in the state has undoubtedly been a major influence in this change. Sugar beet and wheat prices also declined significantly in variance over time, probably traceable to administered price programs. The other significant shifts over time in Table A-1 occurred in the expected upward direction. In practically every case,

${ }^{24}$ Note that the coefficient of random variability expresses the standard deviation relative to the mean of the sub-time period, not relative to the mean of the last five years as in the text. The purpose in the appendix discussion is quite different from the main text in that major interest here is in changes over time, not in predicting relative variability for the future. 
relative variability (measured by the coefficient of random variability) over time for field crops declined.

Table A-2 presents a two-period analysis for vegetable crops. Seven of the 30 vegetable crops changed significantly in yield variance over time. Only two of these (garlic and early fall tomatoes) declined. Early fall tomato yields probably declined in variability mainly because of a shift in location to more favorable soils and climatic conditions (from the Sacramento Valley to the San Joaquin Valley). Sixteen of the 30 vegetables changed significantly in absolute price variability over time, all of them upward. In terms of relative variability, about half the changes in Table A-2 are upward, the other half downward. Perhaps this is indicative of the relatively high risk and uncertainty associated with vegetable production compared with field crop production.

Table A-3 summarizes results of the two-period analysis for fruit and nut crops. Eight of 19 crops changed significantly in absolute yield variance, all of them upward. The alternate bearing tendency for fruits and nuts remains strong even at high yield levels, tending to increase absolute yield variance as yields rise. Ten of 19 crops changed significantly in absolute price variance over time; almonds, cherries, figs, grapes and olives increased, while avocados, grapefruit, oranges (navel), oranges (valencia) and clingstone peaches decreased. Changes in price variability for these crops appear to be related to the degree of organization of the industry. Changes in relative variability for fruits and nuts fall intermediate between changes observed for field crops and for vegetables. About two-thirds of the changes over time in relative variability (coefficient of random variability) for fruits and nuts are downward.

\section{APPENDIX B}

Table B-1 presents comparisons of yield variability estimates for sugar beets on selected farms in Yolo County. Although these farms were not a random sample of this area they provide the basis for a crude comparison of yield variability between geographic areas of different sizes; i.e., between individual producing units, the county, and the state as a whole. ${ }^{25}$ These data appear to support the hypothesis that considerable individual farm yield variability is "averaged out" when state or even county series are used. How much of the measured variability on these individual farms is related to "uncertainty" and how much to varying levels of factor inputs, managerial ability, farm tenure situation and other influencing factors? An extremely detailed analysis of each individual farm situation would be required to determine this.

Tables B-2, B-3, B-4 and B-5 compare yield variability estimates between the leading producing counties and the state as a whole for cotton, rice, barley and sugar beets, respectively. No reliable county yield series were available for other crops. Nor were crop price series by counties available.

Table B-2 indicates that relative cotton lint yield variability (i.e., the yield dispersion relative to the 1953-1957 mean yield as measured by the vari-

\footnotetext{
${ }^{25}$ Sugar beets is the only crop where historical yield series on individual farms were obtainable. Yield records on selected farms for a 15-20 period were obtained from the Yolo County Agricultural Stabilization and Conservation Office.
} 


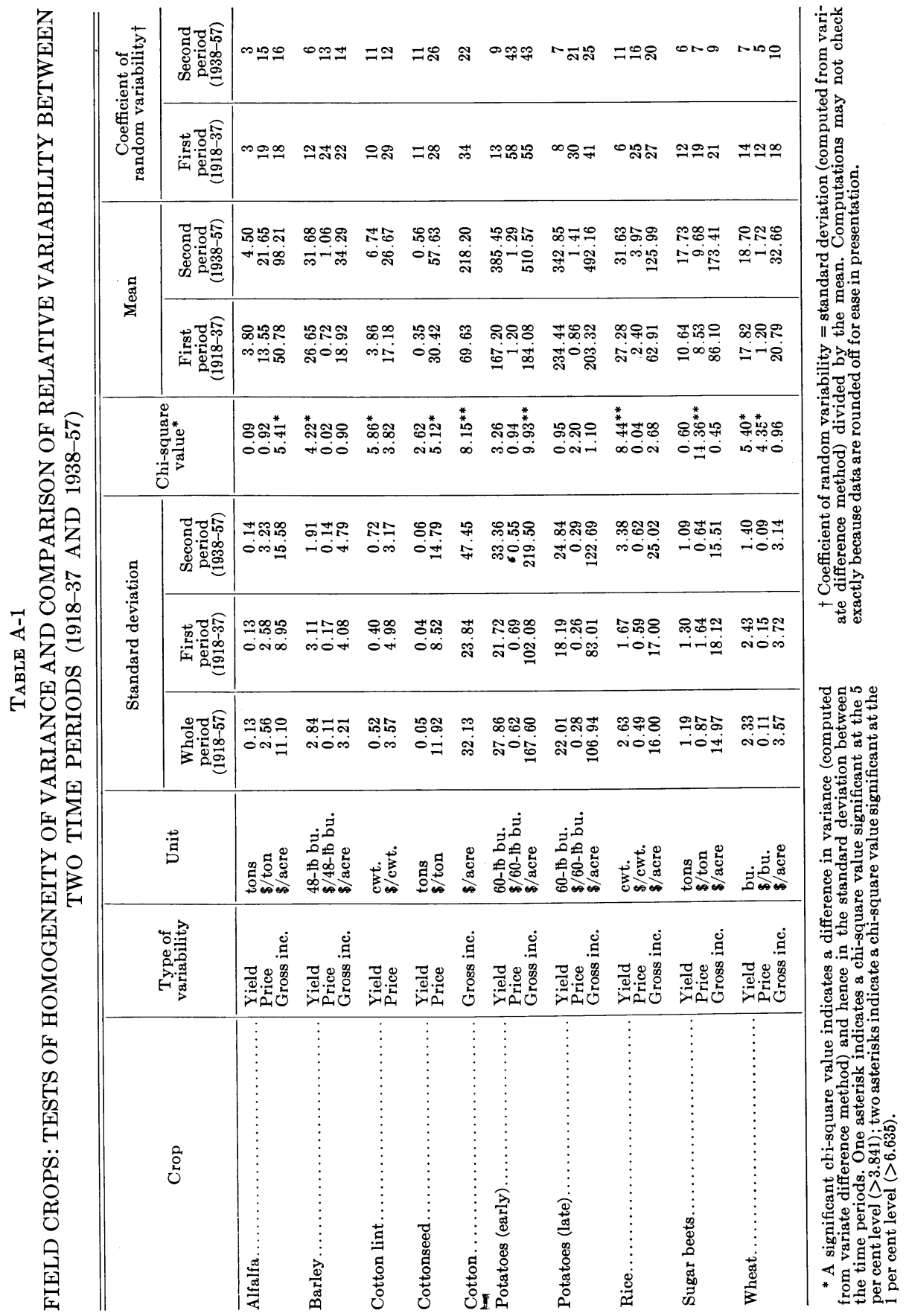




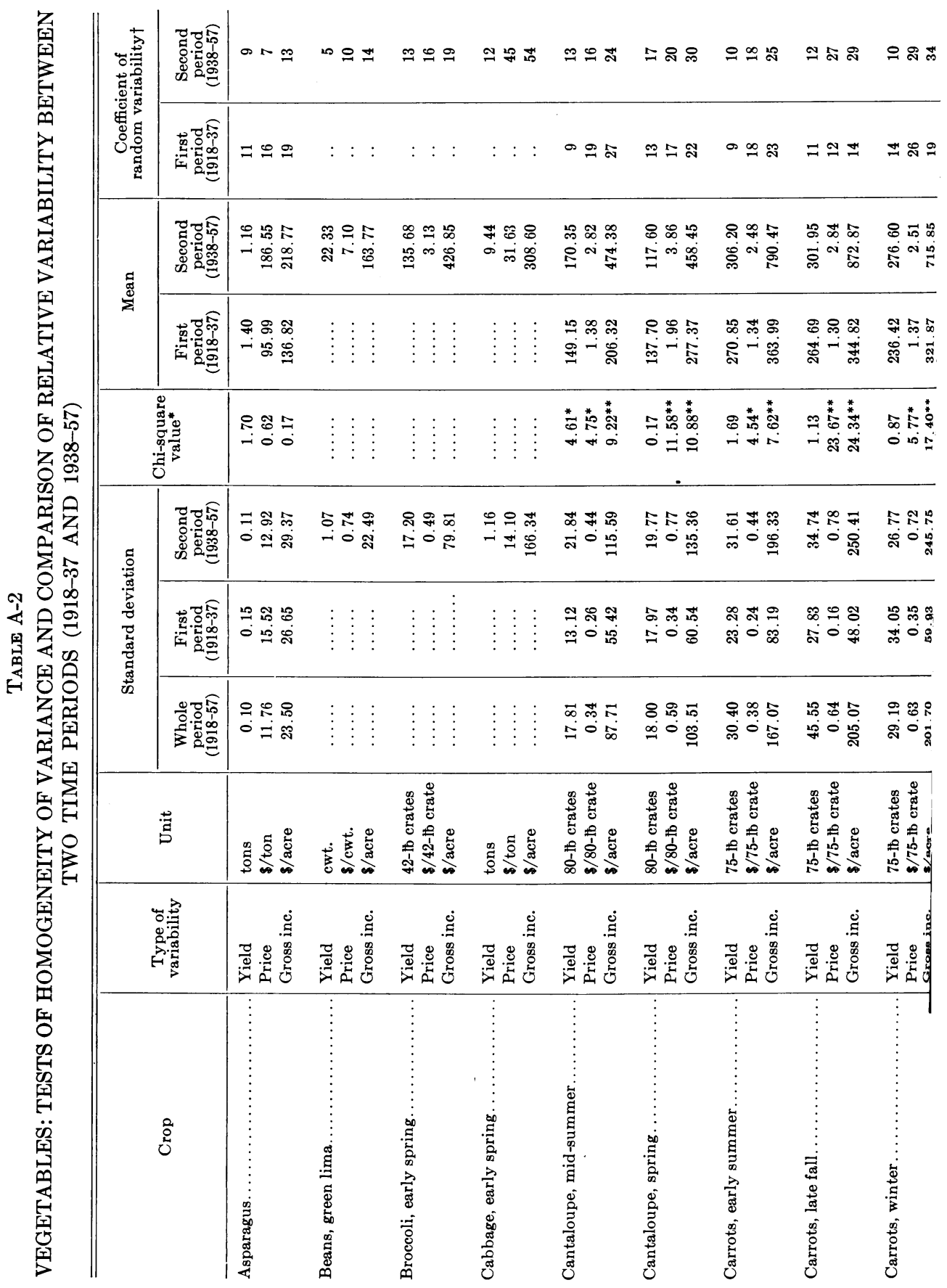


뜹

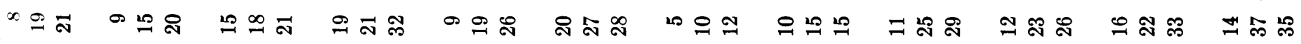

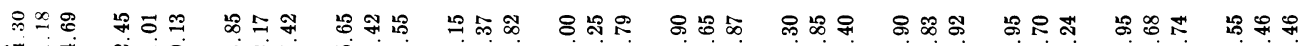

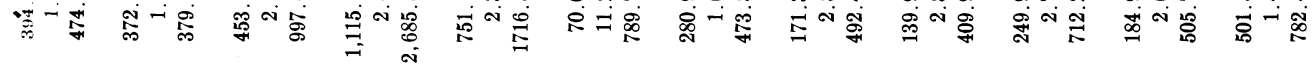

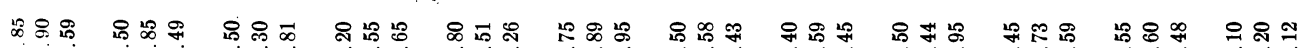

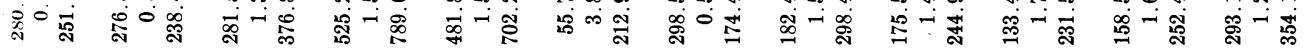

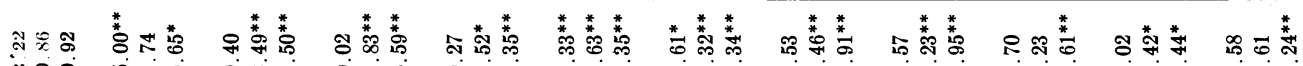
○0 म-

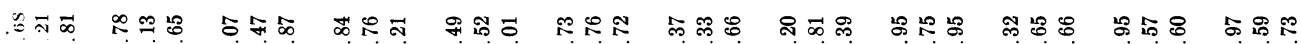

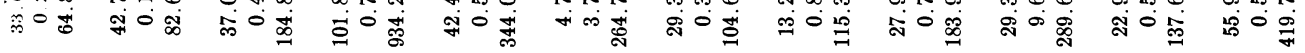

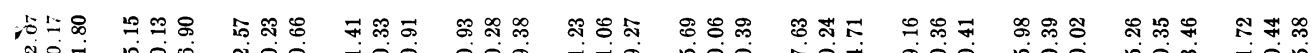

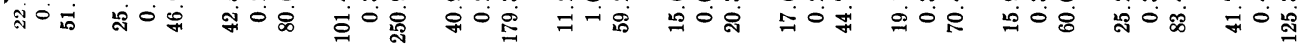

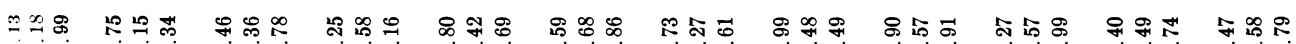

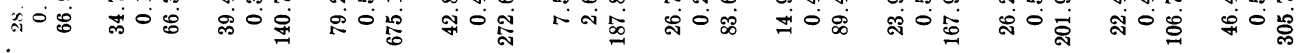

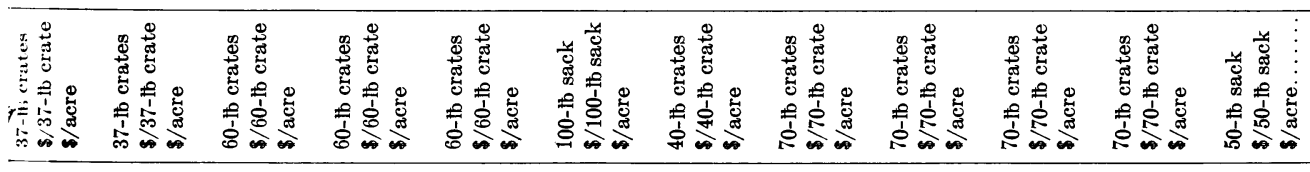

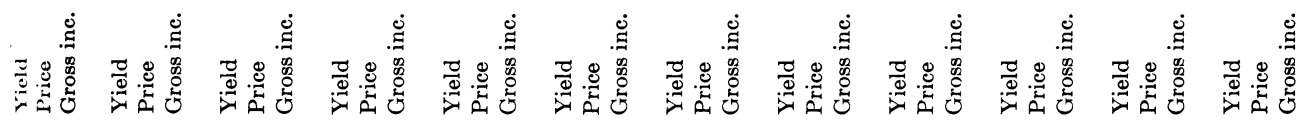

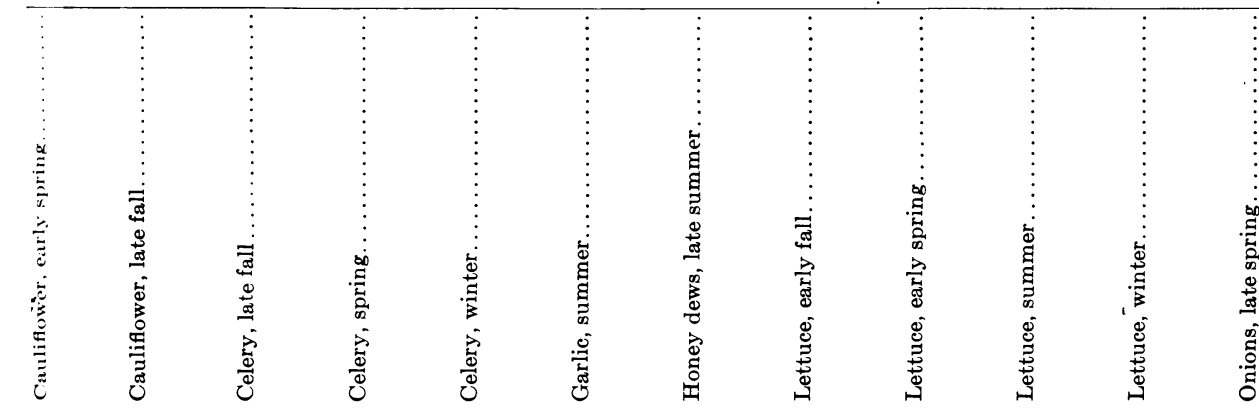




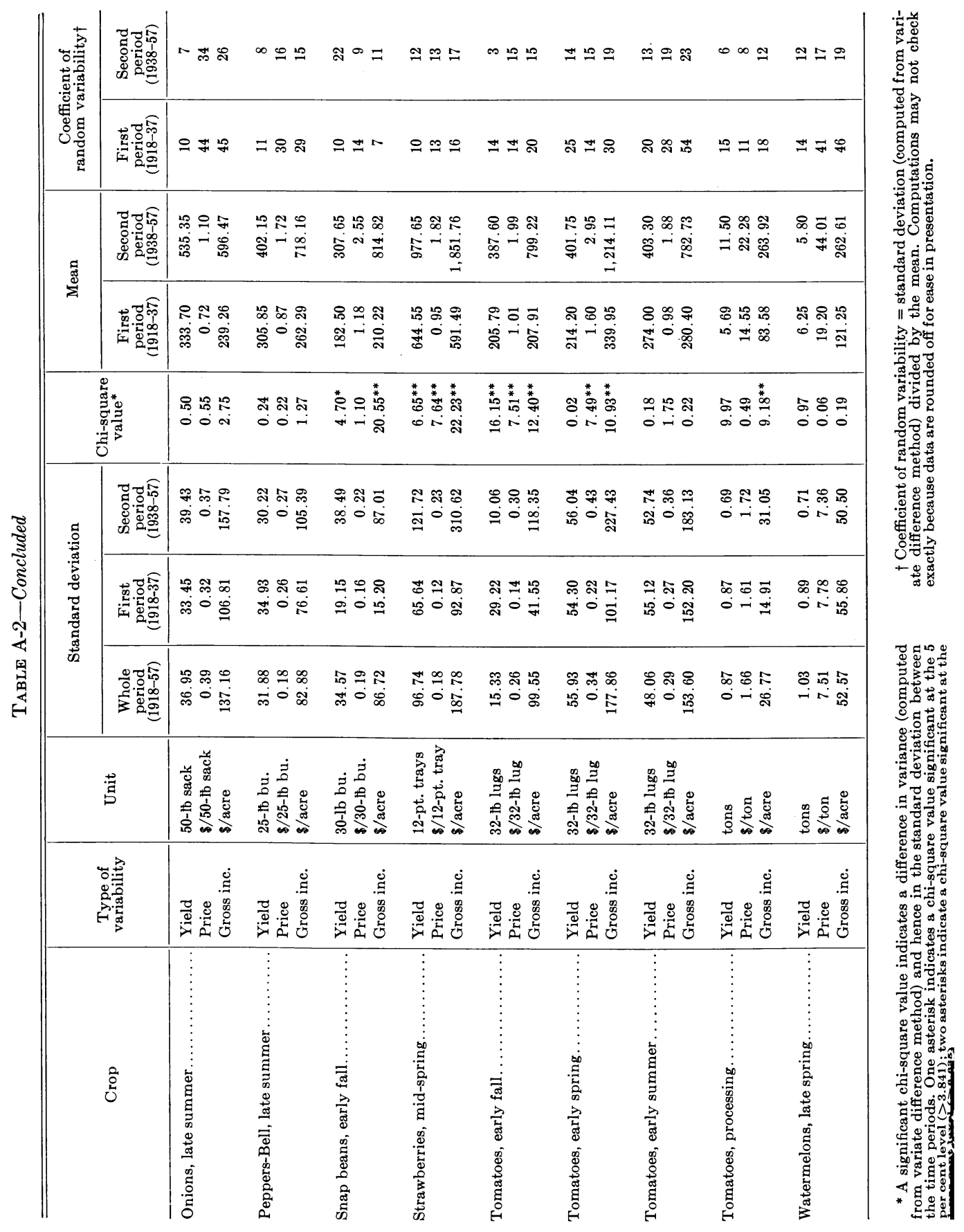


ability coefficient) between counties and for California (as a whole) is minor. ${ }^{26}$ Although the relative yield variability appears fairly uniform between the major areas, the mean yields are slighly lower in Kings and Tulare as compared with Kern and Imperial counties. This difference (although not statistically significant) might be explained by the fact that in both Kings and Tulare counties considerable "new" land has been developed and planted to cotton; in many cases this land has been poorer in quality than the cotton land in Kern and Imperial counties. In both Kings and Tulare counties cotton acreage competes with fruit crops for higher quality land.

Relative yield variability and absolute yield variability of rice between the major producing counties is small ${ }^{27}$ (Table B-3). Small differences are observed between county yield variability measures and California as a whole. Apparently, important factors affecting rice yield fluctuations occur fairly uniformly over these major producing counties located in the Sacramento Valley. These counties are quite similar with respect to environmental factors important in rice production; i.e., a long, warm growing season, freedom from rains during harvest, adequate irrigation water and moisture-retentive soils.

Table B-4 shows that the relative yield variability of barley between the major producing counties is quite small. As a group, the predominantly dry land areas (Monterey, Colusa and Yolo) have slightly greater relative variability than the irrigated areas (Fresno, Kings, and Imperial). The barley yield variances for the six counties are not significantly different at the 95 per cent level. ${ }^{28}$

The four counties shown in Table B-5 account for about 55 per cent of the sugar beet production (by value) in California. Relative sugar beet yield variability between the principal producing counties varies from 8 (Yolo County) to 13 (Kern County). Absolute variability (as indicated by the standard deviation) varies from 1.52 tons (Yolo County) to 3.02 tons (Kern County). ${ }^{29}$ The absolute variance for the state as a whole is 1.07 tons. The greater variability in the Kern County area is associated with the fact that (1) it is a relatively new area of production and consequently has less stable production practices, and (2) excessive insect damage has increased year-toyear fluctuations. The Yolo County area, on the other hand, has been producing sugar beets over a longer period of time and has developed more stable production practices, perhaps accounting for the slightly lower yield variability.

${ }^{20}$ A chi-square value of 2.79 was computed using Bartlett's test of homogeneity of variance. This value indicates that yield variances between these five counties and the state are not significantly different at the 95 per cent level.

${ }^{27}$ Variance of rice yield between counties was nonsignificant at the 95 per cent level according to the Bartlett's test of homogeneity of variance.

${ }^{28}$ Based on Bartlett's test of homogeneity of variance.

${ }^{29} \mathrm{~A}$ chi-square value of 16.14 indicates (using Bartlett's test of homogeneity of variance) that sugar beet yield variances between counties are statistically different at the 95 per cent level. 


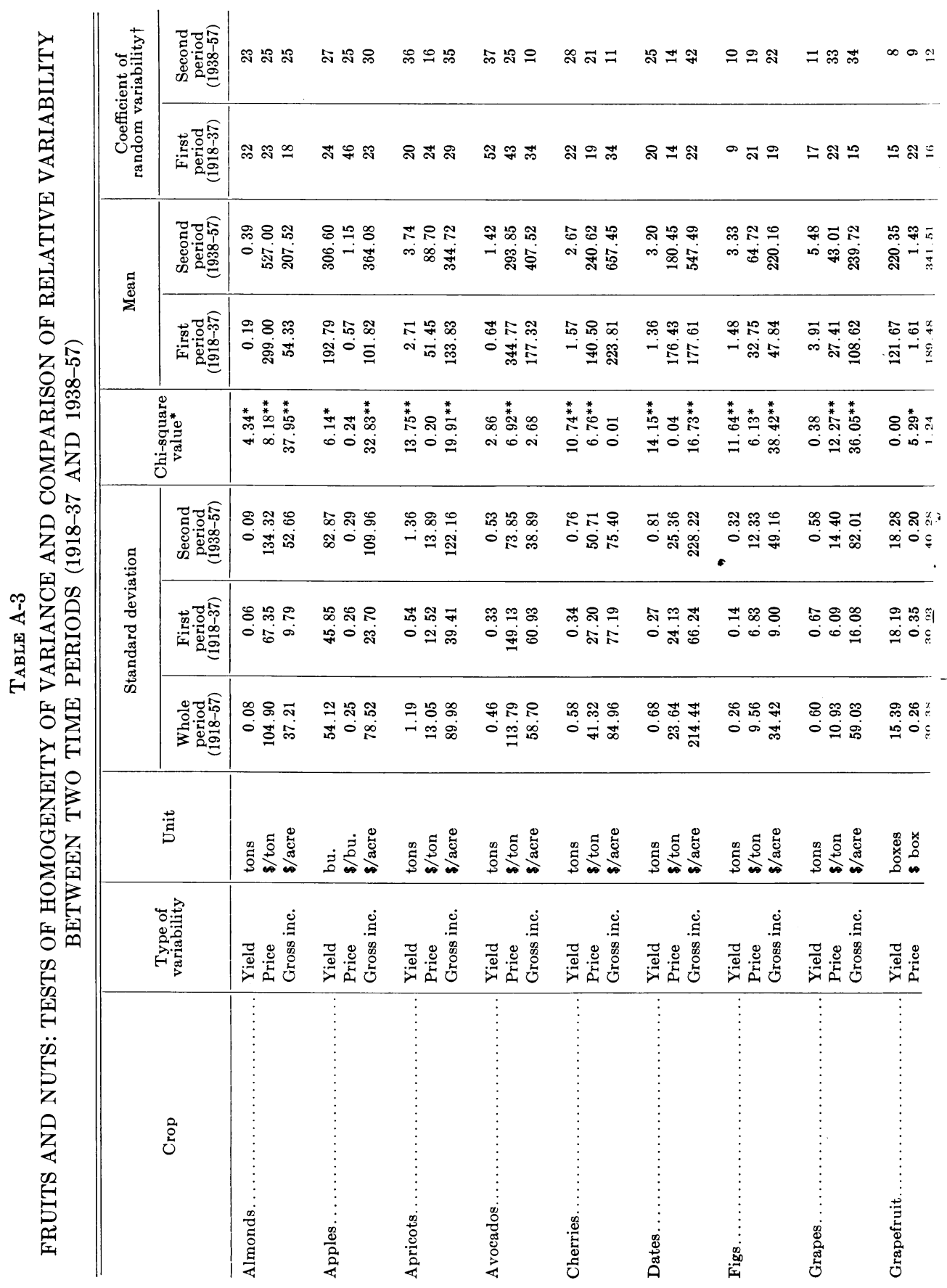




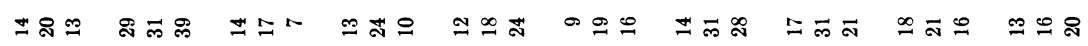

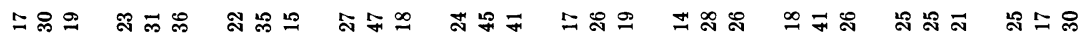

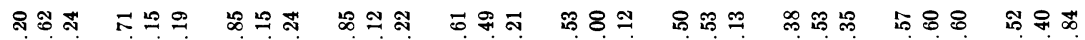

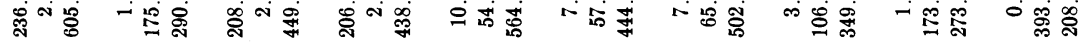

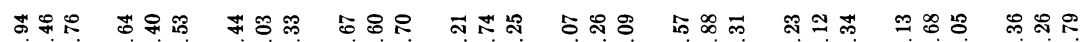

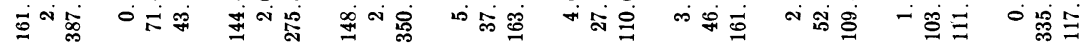

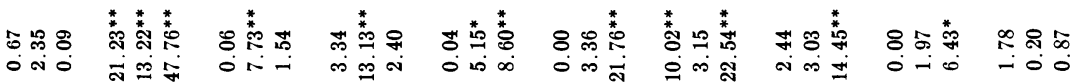

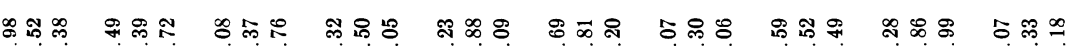

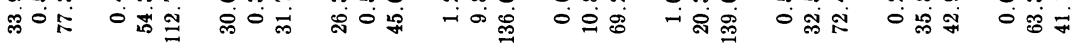

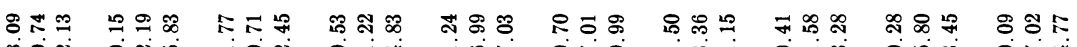

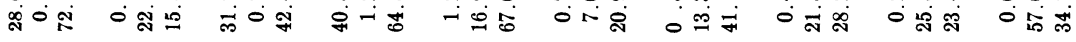

ฌำำ

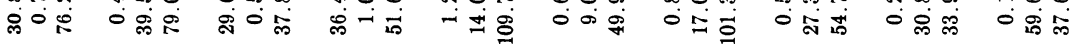

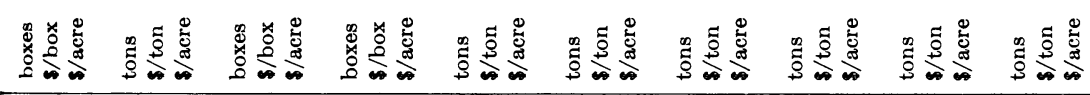

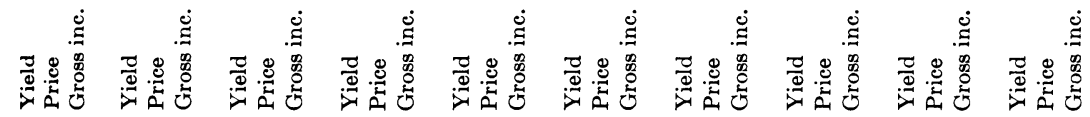

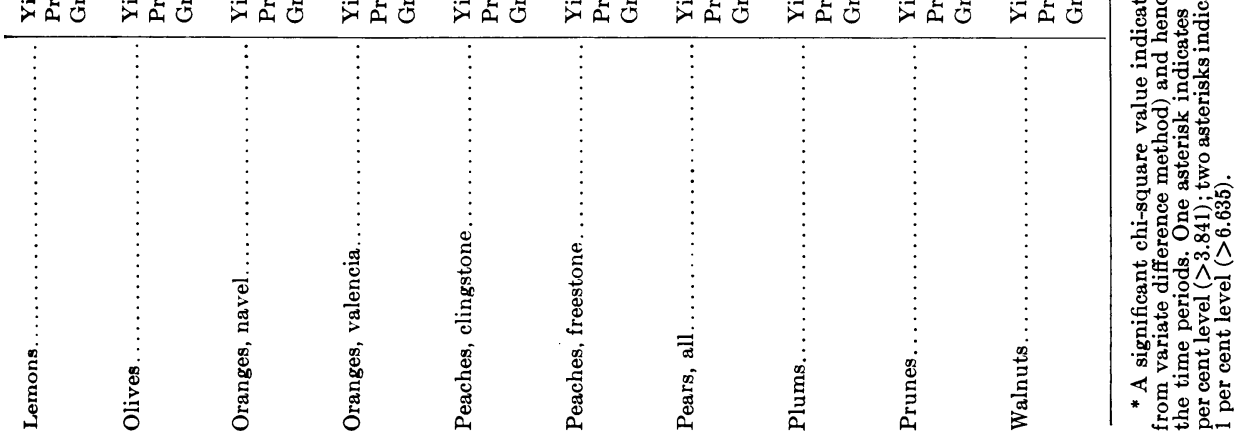


TABLE B-1

COMPARISON OF SUGAR BEET YIELD VARIABILITY BETWEEN SELECTED YOLO COUNTY FARMS, YOLO COUNTY, AND CALIFORNIA

\begin{tabular}{|c|c|c|c|}
\hline Economic unit & $\begin{array}{l}\text { Variability } \\
\text { coefficient* }\end{array}$ & $\begin{array}{l}\text { Standard } \\
\text { deviation }\end{array}$ & $\begin{array}{c}1953-57 \\
\text { mean }\end{array}$ \\
\hline & per cent & tons & tons \\
\hline Yolo farm No. 1.. & 17 & 3.14 & 18.21 \\
\hline No. 2 . & 8 & 1.54 & 19.93 \\
\hline No. $3 .$. & 14 & 2.39 & 17.26 \\
\hline No. $4 \ldots$ & 28 & 3.24 & 11.43 \\
\hline No. $5 \ldots \ldots \ldots \ldots \ldots \ldots \ldots$ & 19 & 2.97 & 22.75 \\
\hline No. $6 \ldots \ldots \ldots \ldots \ldots \ldots \ldots$ & 18 & 3.08 & 17.00 \\
\hline No: $7 \ldots \ldots \ldots \ldots \ldots \ldots \ldots$ & 14 & 2.54 & 18.34 \\
\hline No. $8 \ldots \ldots \ldots \ldots \ldots \ldots \ldots$ & 19 & 3.11 & 16.62 \\
\hline No. $9 \ldots \ldots \ldots \ldots \ldots \ldots \ldots$ & 14 & 2.77 & 20.55 \\
\hline No. $10 \ldots \ldots \ldots \ldots \ldots \ldots \ldots$ & 15 & 3.33 & 22.71 \\
\hline No. $11 \ldots \ldots \ldots \ldots \ldots$ & 15 & 3.74 & 24.54 \\
\hline No. $12 \ldots \ldots \ldots \ldots \ldots \ldots$ & 21 & 3.59 & 16.73 \\
\hline No. $13 \ldots \ldots \ldots \ldots \ldots \ldots$ & 11 & 2.61 & 23.67 \\
\hline No. $14 \ldots \ldots \ldots \ldots$ & 20 & 2.99 & 15.21 \\
\hline No. $15 \ldots$ & 21 & 3.88 & 18.32 \\
\hline No. $16 \ldots \ldots \ldots \ldots \ldots \ldots$ & 20 & 4.64 & 23.16 \\
\hline Yolo County... & 8 & 1.52 & 19.75 \\
\hline California. & 5 & 1.07 & 19.92 \\
\hline
\end{tabular}

* Variability coefficient $=$ standard deviation (computed from variate difference method) divided by 1952-56 mean. Computations may not check because data are rounded off for ease in presentation.

TABLE B-2

COMPARISON OF COTTON (LINT) YIELD VARIABILITY BETWEEN SELECTED COUNTIES AND CALIFORNIA

\begin{tabular}{|c|c|c|c|}
\hline Economic area & $\begin{array}{l}\text { Variability } \\
\text { coefficient* }\end{array}$ & $\begin{array}{l}\text { Standard } \\
\text { deviation }\end{array}$ & $\begin{array}{c}1953-57 \\
\text { mean }\end{array}$ \\
\hline & per cent & pounds & pounds \\
\hline Fresno County ................. & 9 & 75.5 & 857.2 \\
\hline Kings County ................ & 10 & 73.0 & 749.6 \\
\hline Tulare County $\ldots \ldots \ldots \ldots \ldots \ldots \ldots$ & 8 & 56.8 & 721.2 \\
\hline Kern County................... & 7 & 67.8 & 990.6 \\
\hline Imperial County. . & 7 & 63.7 & 906.0 \\
\hline California.......... & 7 & 60.5 & 828.4 \\
\hline
\end{tabular}

* Variability coefficient $=$ standard deviation (computed from variate difference method) divided by 1953-57 mean yield. Computations may not check exactly because data are rounded off for ease in presentation. 
TABLE B-3

COMPARISON OF RICE YIELD VARIABILITY BETWEEN SELECTED COUNTIES AND CALIFORNIA

\begin{tabular}{|c|c|c|c|}
\hline Economic area & $\begin{array}{l}\text { Variability } \\
\text { coefficient* }\end{array}$ & $\begin{array}{l}\text { Standard } \\
\text { deviation }\end{array}$ & $\begin{array}{c}1953-57 \\
\text { mean }\end{array}$ \\
\hline & per cent & pounds & pounds \\
\hline Butte County .................. & 14 & 471.0 & 3,470 \\
\hline Colusa County .................. & 15 & 515.6 & 3,490 \\
\hline Glenn County................. & 17 & 595.9 & 3,520 \\
\hline Sutter County.... & 12 & 450.3 & 3,620 \\
\hline Yolo County.............. & 14 & 474.9 & 3,390 \\
\hline California $\ldots \ldots \ldots \ldots \ldots \ldots \ldots \ldots$ & 13 & 434.1 & 3,440 \\
\hline
\end{tabular}

* Variability coefficient $=$ standard deviation (computed from variate difference method) divided by 1953-57 mean yield. Computations may not check exactly because data are rounded off for ease in presentation.

TABLE B-4

COMPARISON OF BARLEY YIELD VARIABILITY BETWEEN SELECTED COUNTIES AND CALIFORNIA

\begin{tabular}{|c|c|c|c|}
\hline Economic area & $\begin{array}{l}\text { Variability } \\
\text { coefficient* }\end{array}$ & $\begin{array}{l}\text { Standard } \\
\text { deviation }\end{array}$ & $\begin{array}{c}1953-57 \\
\text { mean }\end{array}$ \\
\hline & per cent & bushels & bushels \\
\hline Monterey County ............... & 11 & 3.15 & 29.1 \\
\hline Colusa County................. & 9 & 3.23 & 34.5 \\
\hline Yolo County .............. & 8 & 3.45 & 40.9 \\
\hline Fresno County... & 6 & 2.97 & 52.4 \\
\hline Kings County ............ & 7 & 3.23 & 49.6 \\
\hline Imperial County............ & 7 & 3.56 & 50.7 \\
\hline 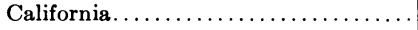 & 5 & 1.91 & 37.7 \\
\hline
\end{tabular}

*Variability coefficient $=$ standard deviation (computed from variate difference method) divided by 1953-57 mean yield. Computations may not exactly check because data are rounded off for ease in presentation.

TABLE B-5

COMPARISON OF SUGAR BEET YIELD VARIABILITY BETWEEN SELECTED COUNTIES AND

CALIFORNIA

\begin{tabular}{|c|c|c|c|}
\hline Economic area & $\begin{array}{l}\text { Variability } \\
\text { coefficient* }\end{array}$ & $\begin{array}{l}\text { Standard } \\
\text { deviation }\end{array}$ & $\begin{array}{c}1952-56 \\
\text { mean }\end{array}$ \\
\hline & per cent & tons & tons \\
\hline Imperial County. & 9 & 1.82 & 20.50 \\
\hline Monterey County. . & 11 & 2.58 & 22.71 \\
\hline Yolo County....... & 8 & 1.52 & 19.75 \\
\hline Kern County.......... & 13 & 3.02 & 22.48 \\
\hline California...... & 5 & 1.07 & 19.92 \\
\hline
\end{tabular}

* Variability coefficient $=$ standard deviation (computed from variate difference method) divided by 1952-56 mean yield. Computations may not check exactly because data are rounded off for ease in presentation. 


\section{APPENDIX C}

\section{The Variate Difference Method}

A brief mathematical explanation of the variate difference method follows. An enlarged treatment is given in Tintner, Gerhard, Ibid., p. 137. The $\mathrm{k}^{\text {th }}$ difference can be defined as:

(a)

$$
\begin{aligned}
& \Delta^{(k)} w_{i}={ }_{k} C_{0} \cdot w_{i+k}-{ }_{k} C_{1} \cdot w_{i+k-1}+{ }_{k} C_{2} \cdot w_{i+k-2}-\cdots \\
& +(-1)_{k}{ }_{k} C_{k} \cdot w_{i}
\end{aligned}
$$

where ${ }_{k} C_{a}$ is the number of combinations of $k$ things taken $a$ at a time; and $w_{i}$ is an economic time series composed of two additive parts:

$$
w_{i}=m_{i}+x_{i}
$$

where $m_{i}=\boldsymbol{E}\left(\boldsymbol{w}_{i}\right)$ and $x_{i}$ is the random element.

The two elements are not correlated (i.e., $E\left(m_{i} x_{j}\right)=0$ ); nor are the random parts correlated with each other (i.e., $E\left(x_{i} x_{j}\right)=0, i \neq j$ ).

The mathematical expectation of $x$ is zero and its population variance $\sigma_{2}$ :

$$
\begin{gathered}
E\left(x_{i}\right)=0 \\
E\left(x_{i}{ }^{2}\right)=\sigma^{2}=\mu_{2}{ }^{(0)}
\end{gathered}
$$

The expectation of the $k^{\text {th }}$ difference of $x$ is:

$$
E\left(\Delta^{(k)} x_{i}\right)=0
$$

Accordingly, the expectation of the square of the difference is:

$$
\begin{aligned}
& E\left(\Delta^{(k)} x_{i}\right)^{2}=E\left({ }_{k} C_{0} \cdot x_{i+k}-{ }_{k} C_{1} \cdot x_{i+k-1}+\cdots\right)^{2} \\
= & E\left({ }_{k} C_{0}{ }^{2} \cdot x_{i+k}{ }^{2}+{ }_{k} C_{1}{ }^{2} \cdot x_{i+k-1}{ }^{2}+\cdots-2 C_{k} C_{0} \cdot{ }_{k} C_{1} \cdot x_{i+k} \cdot x_{i+k-1}+\cdots\right) \\
= & { }_{2 k} C_{k} \cdot E\left(x_{i}{ }^{2}\right)={ }_{2 k} C_{k} \cdot \mu_{2}^{(0)}={ }_{2 k} C_{k} \sigma^{2}
\end{aligned}
$$

Hence, if the population variance of the $k^{\text {th }}$ difference of the random element is:

$$
\sigma_{k}^{2}=\mu_{2}^{(k)} \div{ }_{2 k} C_{k},
$$

the following holds:

$$
\sigma_{0}{ }^{2}=\sigma_{1}{ }^{2}=\sigma_{2}{ }^{2}=\cdots=\sigma^{2} .
$$


That is, if we have eliminated the $m$ (systematic component) in the $k_{o}{ }^{\text {th }}$ difference of $w$ we have:

$$
V_{k_{0}}=V_{k_{0+1}}=V_{k_{0+2}}=\cdots,
$$

where $V_{k}$ is an empirical approximation to $\sigma_{k}^{2}$.

\section{Aggregation Problems}

Aggregation problems are of a primary concern in every economic study; this study is no exception. All variability measures were derived from either state or county time series data. Some of the obvious limitations of estimates derived from such aggregates have been discussed in the text. The following is an attempt to state more explicitly the aggregation problem as it applies in this study.

The yield per acre on the $i^{\text {th }}$ farm is written:

$$
Y_{i t}=\pi_{i}+\theta_{i} t+e_{i t},
$$

where $t=$ time in years, $\pi$ and $\theta$ are parameters, $e$ is the unexplained residual and $i=1,2, \ldots N$.

The usual assumptions are: $E\left(e_{i t}\right)=0$ and $E\left(e_{i t}\right)^{2}=\sigma_{i}{ }^{2}$.

Summing (j) over $N$ farms (all farms producing a particular crop) gives:

$$
\bar{Y}_{t}=\bar{\pi}+\bar{\theta} t+\bar{e}_{t} .
$$

We assume $E\left(\bar{e}_{t}\right)=0$. However, the variance of $\bar{e}_{t}$ is:

$$
\sigma_{\bar{e}_{t}}^{2}=\frac{1}{N^{2}}\left(\sum_{i=1}^{N} \sigma_{i}{ }^{2}+2 \sum_{\substack{i, j=1 \\ i>j}}^{N} \rho_{i j} \sigma_{i} \sigma_{j}\right)
$$

If the assumption $\sigma_{i}{ }^{2}=\sigma^{2}$ is made, (l) may be rewritten as:

$$
\sigma_{\bar{e}_{t}}^{2}=\sigma^{2} / N+2 \sigma^{2} \sum_{i>j} \rho_{i j} / N^{2}
$$

where $\rho_{i j}$ is the correlation between the random yield components on farms $i$ and $j$. Simplifying (m) gives:

$$
\sigma_{\bar{e}_{t}}^{2}=\sigma^{2} / N[1+(N-1) \rho]
$$

Equation (n) shows that $\sigma_{\bar{e}_{t}}{ }^{2}$ (the random variance of the aggregated series) is a function of (1) $N$ (the number of farms making up the aggregate yield) and (2) $\rho$ (the random yield correlation coefficient between farms). If $\rho=1$ (i.e., perfect yield correlation of the random components between farms) $\sigma_{\bar{e}_{t}}{ }^{2}=\sigma^{2}$. The latter assumption (i.e., $\rho=1$ ) is, of course, somewhat unrealistic with respect to crop yield between farms. Where $\rho<1.0$ (and $\sigma_{i}{ }^{2}=\sigma^{2}$ as above), the estimated variance varies inversely with the number of farms making up the aggregate. 
However, with respect to price the corresponding correlation may be close to one; hence, the number of farms making up the aggregate price series would have little influence on the corresponding variance estimate. ${ }^{30}$

\section{Limitations of the Method with Respect to Gross Income Estimates}

Use of the variate difference method for deriving the random variance for gross income involves certain internal inconsistencies. Gross income is defined as the product of price and yield (per acre). Further, yield and price series are each assumed to consist of a systematic and random element as follows:

$$
\begin{gathered}
Y_{t}=\pi+\beta t+e_{t} \quad \text { and } \\
P_{t}=\theta+\delta t+\epsilon_{t}
\end{gathered}
$$

Accordingly, gross income $(G I)$ would be written as:

$$
\begin{aligned}
G I_{t}=Y_{t} \cdot P_{t} & =\pi \epsilon_{t}+\beta t \epsilon_{t}+\epsilon_{t} e_{t}+\delta t \pi \\
+\delta t \beta t & +\delta t e_{t}+\theta \pi+\theta \beta t+\theta e_{t}
\end{aligned}
$$

It is apparent from the product of error and nonerror terms above (e.g., $\beta t_{t}$, $\delta t e_{t}$, etc.) that differencing can never completely eliminate the systematic components from the error terms. Consequently, the variate difference method provides only an approximation to the random variance for gross income.

${ }^{30}$ Equations (i) to (n) would also apply for prices.

HeAdy, E. O.

\section{Literature Cited}

1952. Economics of agricultural production and resource use. Prentice Hall, New York, N.Y.

HeAdy, E. O., E. W. KeHrberg and E. H. Jebe

1954. Economic instability and choices involving income and risk in primary or erop KLING, W. production. Iowa Agr. Exp. Sta. Res. Bul. 404. Ames, Iowa 618-723 pp.

1942. Determination of relative risks involved in growing truck crops. Jour. of Farm Economics (24) $3: 694-698$.

KNIGHT, F. H.

1921. Risk, uncertainty and profit. Houghton Mifflin Co. Boston, Mass.

MCCORKLE, C. O., JR. and M. YAIR

1956. Statistical analysis of supply response in late spring potatoes in California. Hil-

SHultis, A. gardia $24(16): 455-493$.

1951. Farming in California. Ag. Ext. Serv. Berkeley. Circular 173. 50 pp.

SNEDECOR, G. W.

1946. Statistical methods (4th ed.). Iowa State College Press. Ames, Iowa 249-252 pp. TINTNER, G.

1940. The variate difference method. Cowles Commission For Research in Economics. Mimeograph No. 5. Principia Press. Bloomington, Ind. 175 pp.

1952. Econometries. John Wiley and Sons, Ine. New York, N.Y. 312-314 pp. 
The journal Hilgardia is published at irregular intervals, in volumes of about 600 pages. The number of issues per volume varies.

Subscriptions are not sold. The periodical is sent as published only to libraries, or to institutions in foreign countries having publications to offer in exchange.

You may obtain a single copy of any issue free, as long as the supply lasts; please request by volume and issue number from:
Agricultural Publications
207 University Hall
2200 University Avenue
Berkeley 4, California

The limit to nonresidents of California is 10 separate issues on a single order. A list of the issues still available will be sent on request. 